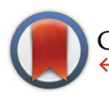

CrossMark \&lick for updates

Cite this: Dalton Trans., 2016, 45 6136

Received 6th October 2015, Accepted 19th November 2015 DOI: $10.1039 / \mathrm{c} 5 \mathrm{dt} 03911 \mathrm{~h}$ www.rsc.org/dalton

\section{Bis-(benzothiazol-2-yl)-amines and their metal amides: a structural comparison in the solid state $+t$}

\author{
David-R. Dauer, Melchior Flügge, Regine Herbst-Irmer and Dietmar Stalke*
}

Within this work, the field of amide ligand platforms for group 13 metal complexation, especially for Al(III) is investigated in a synthetic as well as in a structural comparative approach. Starting from bis-heterocyclo methanides, which mimic the omnipresent nacnac ligand, the next enhancement in this class of ligands includes the exchange of the central methylene bridge by an amine nitrogen atom. With this modification three different sec. amines, each symmetrically substituted, could be synthesised as parent neutral benzothiazole containing ligand systems: $\left(\mathrm{NCSC}_{6} \mathrm{H}_{4}\right)_{2} \mathrm{NH}$ (1), (4-MeNCSC $\left.6 \mathrm{H}_{3}\right)_{2} \mathrm{NH}$ (2) and (4-OMeNCSC $\left.6 \mathrm{H}_{3}\right)_{2} \mathrm{NH}$ (3). Apart from these compounds also a lithiated species and a row of group 13 metal complexes of the deprotonated ligands could be examined by applying single crystal X-ray diffraction analyses. In this course three new dimethyl aluminium containing complexes $\left[\mathrm{Me}_{2} \mathrm{Al}\left\{\left(\mathrm{NCSC}_{6} \mathrm{H}_{4}\right)_{2} \mathrm{~N}\right\}\right]$ (4), $\left[\mathrm{Me}_{2} \mathrm{Al}\left\{\left(4-\mathrm{MeNCSC}_{6} \mathrm{H}_{3}\right)_{2} \mathrm{~N}\right\}\right](5)$ and $\left[\mathrm{Me}_{2} \mathrm{Al}\left\{\left(4-\mathrm{OMeNCSC}_{6} \mathrm{H}_{3}\right)_{2} \mathrm{~N}\right\} \cdot \mathrm{AlMe}_{3}\right]$ (6) as well as two lithiated compounds $\left[\mathrm{Li}\left\{\left(\mathrm{NCSC}_{6} \mathrm{H}_{4}\right)_{2} \mathrm{~N}\right\}\right]_{4}(7)$, [Li $\left.\left\{\left(4-\mathrm{MeNCSC}_{6} \mathrm{H}_{3}\right)_{2} \mathrm{~N}\right\}\right]_{4}(\mathbf{8})$ were structurally and spectroscopically characterised. A subsequent structural comparison of 1-6 and $\mathbf{8}$ in the solid state shows that the parent ligand systems prefer a planar cis-trans alignment due to hydrogen bond formation. In contrast to that, the metallated species favour a planar but trans-trans or cis-cis alignment depending on the metal cation.

\section{Introduction}

The ubiquitous $\beta$-diketiminate ligand (nacnac) is mostly known for its ability to stabilise metal ions in low oxidation states. It enjoys great popularity because the steric and electronic properties can easily be modified by using different substituents at the imine moieties. ${ }^{1}$ A significant advantage of those nacnac ligand systems is e.g. that in the case of the most wide-spread Dipp-substituted derivative (Dipp $=2,6$-diisopropylphenyl) the phenyl entities are twisted nearly perpendicular with respect to the chelating plane of the nacnac backbone. This twisting of the residues causes the coordinated metal ion to be maximally shielded and thus prevented from oligomerisation or electrophilic attacks. ${ }^{2}$ In previous work a binding motif as in nacnac metal complexes was mimicked by replacing the acyclic imine moieties with fused cycles and sub-

Institut für Anorganische Chemie, Georg-August-Universität Göttingen, Tammannstraße 4, 37077 Göttingen, Germany.

E-mail:dstalke@chemie.uni-goettingen.de

$\dagger$ In Memory of Prof. Heinrich Nöth.

\$Electronic supplementary information (ESI) available: Tables of data collection parameters, bond lengths and angles of compounds 1-6 and 8. CCDC 1042655-1042661. For ESI and crystallographic data in CIF or other electronic format see DOI: 10.1039/c5dt03911h sequent deprotonation resulting in a delocalised six electron containing $\pi$-system. Formally the substituents in the backbone of the nacnac ligand are fixed to the imine residue, so that a cyclic heteroaromatic compound is formed. Referring to this, in the early 1990s pyridyl groups were introduced in such kind of ligand systems to generate lithium and group 13 complexes of the monoanionic bis-(pyrid-2-yl)-methanide. ${ }^{3}$ As a further consequence of tuning the coordination ability and electronic properties of this new ligand class also the bridging atom between the two heteroaromates was switched for a group 15 element, wherein the $\mathrm{CH}_{2}$ group of the parent ligand systems is isoelectronically replaced by an $\mathrm{NH}, \mathrm{PH}$ or even AsH group. ${ }^{4}$ Subsequently in the case of the sec. phosphanes the pyridyl moieties were substituted by larger heteroaromates like benzothiazole. This sec. phosphane $\left(\mathrm{NCSC}_{6} \mathrm{H}_{4}\right)_{2} \mathrm{PH}$ was the scaffold of several investigations, wherein the corresponding phosphanide anion acts as a Janus head ligand, containing the soft P-centred and the hard N-centred coordination site. ${ }^{5}$ Furthermore, the corresponding bis-heterocyclo methanides are part of current research. ${ }^{6}$ To continue those investigations the new ligand systems 1-3 were synthesised and characterised in detail. These amine species represent the lighter homologues of the benzothiazole containing phosphanes by switching the bridging atom to the lighter congener. Similarly they can be compared to the dipyridyl amine, because they 


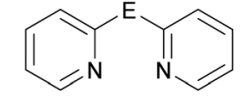

$\mathrm{E}=\mathrm{CH}_{2}, \mathrm{NH}, \mathrm{PH}, \mathrm{AsH}$

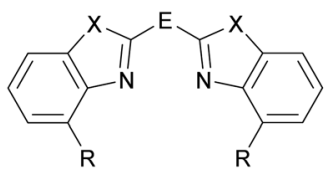

$\begin{array}{lll}\mathrm{E}=\mathrm{CH}_{2} ; & \mathrm{X}=\mathrm{O}, \mathrm{S} ; \quad \mathrm{R}=\mathrm{H}, \mathrm{CH}_{3}\end{array}$
Scheme 1 Introduced comparable ligand types.

just vary in the heterocyclic side arms while the bridging moiety (NH) stays the same (Scheme 1$){ }^{7}$

The derived amides 4-6 (Scheme 5, vide infra) are of special interest regarding their coordination ability, because they offer a magnitude of permutations of suitable donor sites. ${ }^{8}$ Furthermore, the catalytic behaviour of metal complexes containing related amines/amides as ligands plays a vital role in current research. An iridium complex encumbering a phosphane functionalised (di-) pyridyl amine offers easy $N$-alkylation of anilines or amino pyridines ${ }^{9}$ and another iridium complex with 1,3,5-triazine that links between two phosphane functionalised amine moieties acts as a catalyst in pyrrole synthesis. ${ }^{10}$ Moreover, in addition to the well-known bis-(oxazoline)-methane ligand, which is prone to its activity towards asymmetric catalysis, ${ }^{11}$ related species were investigated, wherein the bridging carbon atom is replaced by a nitrogen atom. For example bis(oxazoline)-amines, ${ }^{12}$ 5-aza-semicorrins ${ }^{13}$ and chiral bis-(2pyridylimino)-isoindoles should be mentioned in this context. ${ }^{14}$

\section{Results and discussion}

\section{Syntheses of the ligands}

First the syntheses of the bis-heterocyclo amines will be discussed with respect to the equi-structural bis-heterocyclo methanes. ${ }^{6}$ The vital difference between those two ligand systems is the bridging moiety, which links the two identical benzannulated heterocycles. The methylene unit in the first is now replaced by a sec. amine function.

Different to the methane derivatives, which were synthesised by cyclocondensation reactions for building up the five-membered heterocycles, ${ }^{15}$ for the generation of the symmetrically substituted amines 1-3 two equivalents of the 2-aminobenzothiazole, which could further be substituted at the 4-position of the annulated $\mathrm{C}_{6}$-perimeter, in the presence of 1.4 eq. phenol were employed (Scheme 2). ${ }^{16}$ Thus three different ligands could be synthesised and characterised. X-ray crystallographic studies of the parent ligands enable to quantify their arrangement in the solid state. The molecular structures of the benzothiazole containing compounds 1-3 could be obtained and discussed in detail. Also the synthesis of the benzoxazole containing derivative $\mathbf{9}$ was achieved by using 2-aminobenzoxazole as starting material, but due to the small yields and poor solubility no crystals suitable for single crystal X-ray diffraction could be grown.

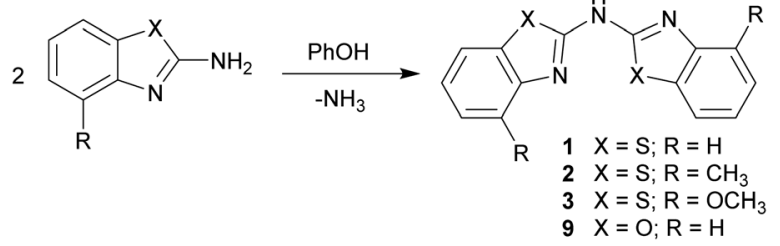

Scheme 2 Synthetic route to the parent ligand systems 1-3 and 9.

\section{Structural comparison of 1-3}

Compound 1 (Fig. 1 and 2) crystallises in the monoclinic space group $P 2_{1}$ and the asymmetric unit contains a single molecule. The methyl substituted parent ligand 2 however (Fig. 3) crystallises in the triclinic space group $P \overline{1}$ with two molecules and half a toluene molecule located at an inversion centre in the asymmetric unit, while the methoxy derivative 3 (Fig. 4) crystallises in the monoclinic space group $C 2 / c$. The asymmetric unit

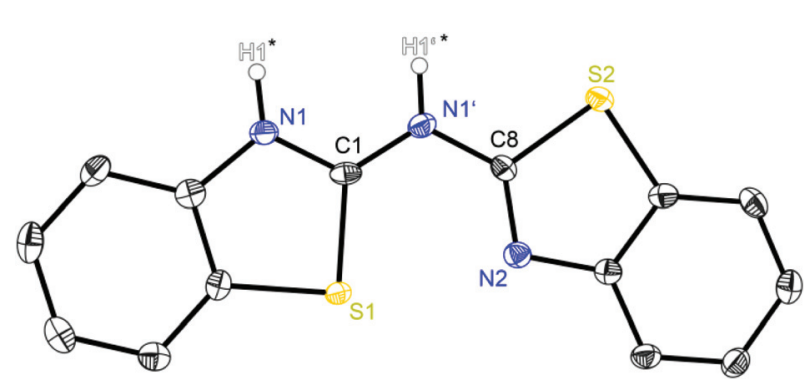

Fig. 1 Molecular structure of $\left(\mathrm{NCSC}_{6} \mathrm{H}_{4}\right)_{2} \mathrm{NH}$ (1). Anisotropic displacement parameters are depicted at the $50 \%$ probability level. $\mathrm{C}-\mathrm{H}$ hydrogen atoms are omitted for clarity. Both hydrogen atoms of the amine moieties highlighted with a star are only partially occupied due to their positional disorder. Structural data are given in Tables 1-3.

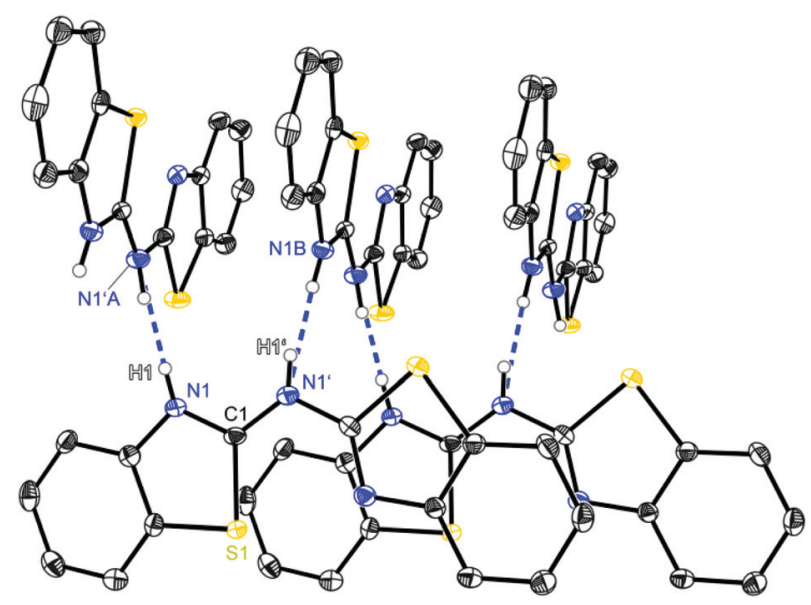

Fig. 2 Molecular structure of a hydrogen bridged chain of $\left(\mathrm{NCSC}_{6} \mathrm{H}_{3}\right)_{2} \mathrm{NH}$ (1). Anisotropic displacement parameters are depicted at the $50 \%$ probability level. $\mathrm{C}-\mathrm{H}$ hydrogen atoms are omitted for clarity. Structural data are given in Tables 1-3. 


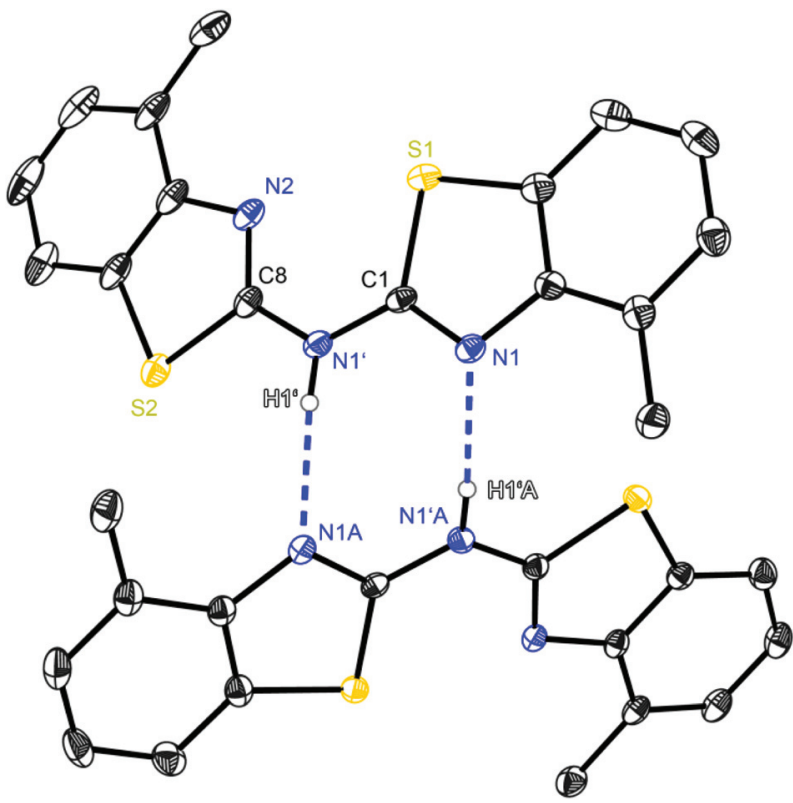

Fig. 3 Molecular structure of a hydrogen bridged dimer of (4- $\left.\mathrm{MeNCSC}_{6} \mathrm{H}_{3}\right)_{2} \mathrm{NH}$ (2). Anisotropic displacement parameters are depicted at the $50 \%$ probability level. $\mathrm{C}-\mathrm{H}$ hydrogen atoms are omitted for clarity. Structural data are given in Tables 1-3.

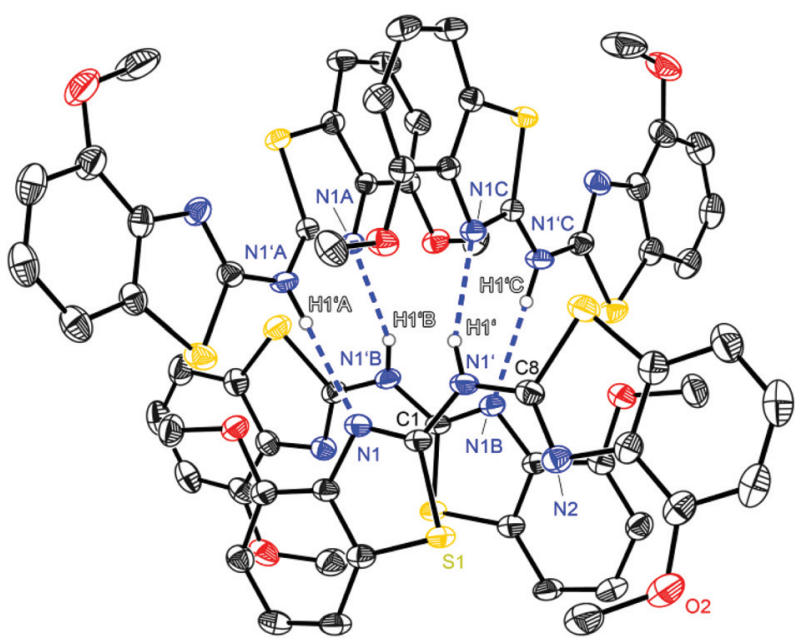

Fig. 4 Molecular structure of a hydrogen bridged tetramer of (4-OMeNCSC $\left.{ }_{6} \mathrm{H}_{3}\right)_{2} \mathrm{NH}$ (3). Anisotropic displacement parameters are depicted at the $50 \%$ probability level. $\mathrm{C}-\mathrm{H}$ hydrogen atoms are omitted for clarity. Structural data are given in Tables 1-3.

here consists also of two ligands with a whole co-crystallised toluene molecule (Table 4). Each determined crystal structure of the three related ligand systems 1-3 shows the presence of structure-determining hydrogen bonds between the amine moiety as a hydrogen bond donor and an imine moiety of a neighbouring molecule as a hydrogen acceptor. ${ }^{17}$ Furthermore, both heteroaromatic residues are oriented to different directions in the solid state. Referring to the hydrogen bonding properties the position of the amine proton is not fixed and varies within the discussed ligand systems (vide infra).

All ligands adopt a nearly planar arrangement (Fig. 1-4) because the central trivalent nitrogen atom exhibits a $\mathrm{sp}^{2}$ hybridisation. The angular sum at the bridging nitrogen atom with respect to the ring pivot carbon atoms and the freely refined hydrogen atom position gives $360(2)^{\circ}$ in 2 and in 3 , which clearly indicates $\mathrm{sp}^{2}$-hybridisation. The angular sum in 1 at N1' cannot be determined unambiguously due to the positional disorder of the amine hydrogen atom. The positions of the other hydrogen atoms are taken from the difference Fourier map and refined freely with their site occupation factors adding up to 1 . Thus three different configurational isomers are conceivable with each benzothiazole substituent inclined to two possible orientations in such a planar setting: cis or trans. Analogue to earlier structural investigations of related ligand systems like di(pyrid-2-yl)-amides and -phosphanides a classification for those three configurational isomers is described in Scheme $3 .^{4 c, 18}$ In contrast to this, the related methylene bridged derivatives $\left(\mathrm{NCOC}_{6} \mathrm{H}_{4}\right)_{2} \mathrm{CH}_{2}{ }^{6 b}\left(\mathrm{NCSC}_{6} \mathrm{H}_{4}\right)_{2} \mathrm{CH}_{2}{ }^{6 b}$ and $\left(4-\mathrm{MeNCOC}_{6} \mathrm{H}_{3}\right)_{2} \mathrm{CH}_{2}{ }^{6 a}$ do not show a planar arrangement of the heterocyclic residues, but rather the coordination geometry of the bridging carbon atom is distorted tetrahedral.

The used cis-trans nomenclature distinguishes the arrangement of the highest priority atom, the chalcogen atom, with respect to the partially present $\mathrm{C}_{i p s o}=\mathrm{N}_{\text {bridge }}$ double bond. The most stable conformation of $\mathbf{1 - 3}$ is the one with one heterocycle cis- and the other trans-arranged as deduced from the crystal structures.

Following the description of the different conformers in principal there is the additional option for an imine-enaminetautomerism, depicted in Scheme 4 for the observed cis-trans arrangement. This implies that three different tautomeric isomers might occur, in which one of them encloses two $\mathrm{C}_{\text {ipso }}=\mathrm{N}_{\text {het }}$ double bonds (form b) and both others consist each of one $\mathrm{C}_{i p s o}=\mathrm{N}_{\text {het }}$ and one exocyclic $\mathrm{C}_{i p s o}=\mathrm{N}_{\text {bridge }}$ double bond (forms a and $\mathbf{c}$ ). These structures determine the position

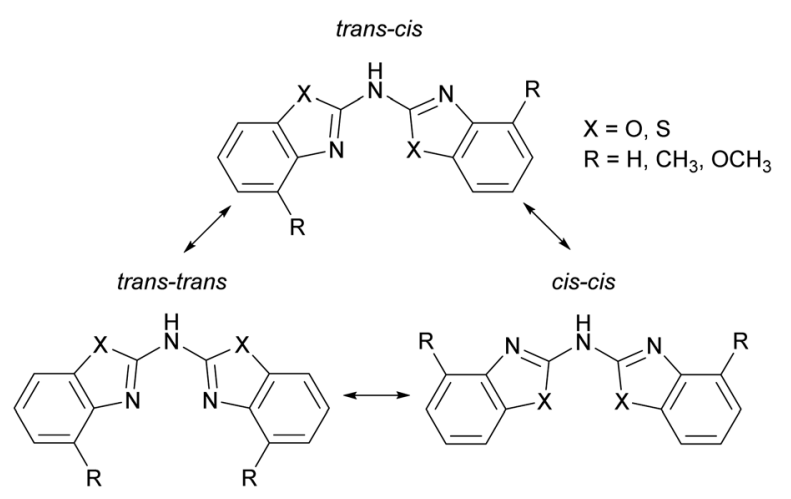

Scheme 3 Three possible configuration isomers of the bis-heterocyclic substituted amines $1-3$. 


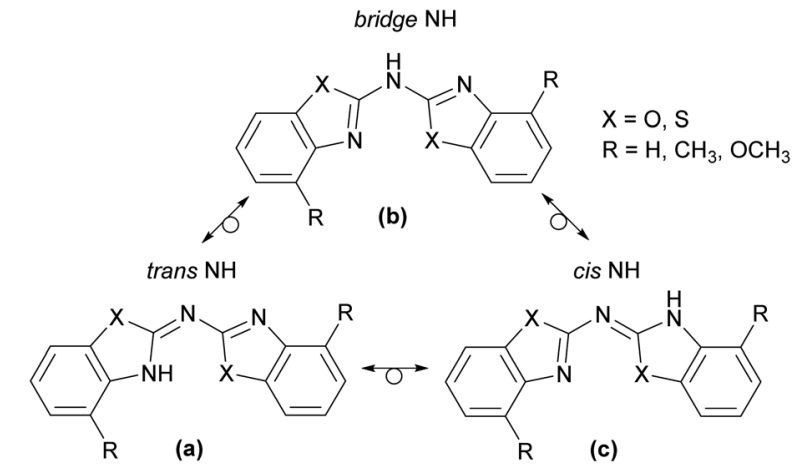

Scheme 4 Imine-enamine tautomerism in cis-trans conformers of 1-3.

of the amine hydrogen atom. In form $\mathbf{b}$ there is a clear separation between the two conjugated, aromatic heterocycles by the bridging $\mathrm{NH}$ spacer. In a and $\mathbf{c}$ one of the endocyclic $\mathrm{C}_{i p s o}=\mathrm{N}_{\text {het }}$ double bonds has tautomerised to an exocyclic $\mathrm{C}_{\text {ipso }}=\mathrm{N}_{\text {bridge }}$ double bond. Thus the bridging nitrogen atom is left two-coordinated and one heterocyclic N-atom gets protonated to adopt the sec. amine functionality. Indeed, such a tautomerism is already established with heterocyclic substituted sec. phosphanes. ${ }^{4 a, 19}$ With a diimine form $\mathbf{b}$ and the two imino-enamine forms a and $\mathbf{c}$ it was only discussed recently at the well-known ligand platform of bis-(oxazoline)-methane. ${ }^{20}$

With regard to the latter cases two possible positions for the $\mathrm{NH}$ hydrogen atom can be envisaged, depending on whether the hydrogen atom is bonded to the cis or to the trans aligned part of the molecule. So the trans $\mathrm{NH}$ in $\mathbf{a}$ is prone to intramolecular hydrogen bonding to the adjacent chalcogen acceptor within the other heterocyclic substituent and the cis $\mathrm{NH}$ is more exposed to intermolecular hydrogen bonding to neighbouring molecules in the unit cell.

Considering this conformational and tautomeric freedom, the following decisive observations in the solid state can be made: in any case of the parent protonated ligands 1-3 the cis-trans arrangement is favoured associated with the organic substituents at the annulated benzene perimeters pointing to opposite directions to reduce steric interaction. This cis-trans configuration is also present in most polymorphs known of the dipyridyl amine ligand. ${ }^{7}$ However, in bis-(benzothiazol-2yl)-phosphane the trans-trans configuration is preferred in the solid state, where it is shown that the hydrogen atom is located at one nitrogen atom of the benzothiazole unit to form an intramolecular hydrogen bond between both ring nitrogen atoms. The bridging phosphorus remains two-coordinate. ${ }^{5 c, d}$ This difference can be explained by the higher Lewis basicity of the nitrogen atoms compared to phosphorus, so that the formed $\mathrm{N}-\mathrm{H}$ bonds and the resulting $\mathrm{N}-\mathrm{H} \cdots \mathrm{N}$ hydrogen bonds are energetically more advantageous.

The crystal structure of 1 in Fig. 1 reveals a significant fraction of the tautomers $\mathbf{b}$ and $\mathbf{c}$ because the remaining electron density at the nitrogen atoms $\mathrm{N} 1$ and N1' is a clear sign for the presence of a $\mathrm{NH}$ hydrogen atom. Due to the positional disorder in the solid state the hydrogen atoms $\mathrm{H} 1$ ' and $\mathrm{H} 1$ can be refined in a ratio of approximately $1: 2$, indicating that form $\mathbf{c}$ is slightly favoured in the solid state. Table 1 shows two different $\mathrm{C}_{\text {ipso }}-\mathrm{N}_{\text {bridge }}$ bond lengths with the $\mathrm{C} 1-\mathrm{N} 1{ }^{\prime}$ distance to be about $0.03 \AA$ shorter than the $\mathrm{C} 8-\mathrm{N} 1{ }^{\prime}$ bond (1.336 $\AA$ vs. $1.367 \AA$ ). Furthermore, the endocyclic $\mathrm{C}_{i p s o}-\mathrm{N}_{\text {het }}$ bond lengths deviate significantly (C1-N1: $1.331 \AA$ A C8-N2: $1.301 \AA$ ). These findings document alternating $\mathrm{C}-\mathrm{N}$ and $\mathrm{C}=\mathrm{N}$ bonds, with $\mathrm{C} 1=\mathrm{N} 1{ }^{\prime}$ and $\mathrm{C} 8=\mathrm{N} 2$ to be double bonds and $\mathrm{C} 1-\mathrm{N} 1$ and $\mathrm{C} 8-$ N1' single bonds. This pattern would also explain the tautomeric form $\mathbf{c}$ and the deviations of the observed bond lengths from $\mathrm{C}\left(\mathrm{sp}^{2}\right)-\mathrm{N}\left(\mathrm{sp}^{2}\right)$ single $(1.40 \AA)$ and $\mathrm{C}\left(\mathrm{sp}^{2}\right)=\mathrm{N}\left(\mathrm{sp}^{2}\right)$ double bonds $(1.29 \AA)^{21}$ are due to the presence of the other isomer $\mathbf{b}$.

In the structures 2 and 3 (Fig. 3 and 4) the amine functionality could only be observed at the bridging position at $\mathrm{N} 1^{\prime}$ indicating the presence of exclusively form $\mathbf{b}$. Additionally the $\mathrm{C}_{\text {ipso }}-\mathrm{N}_{\text {bridge }}$ bond lengths compiled in Table 1 show nearly the same values: $1.374 / 1.370 \AA$ for 2 and 1.363/1.365 $\AA$ for 3 . These bond lengths range between a $\mathrm{C}\left(\mathrm{sp}^{2}\right)-\mathrm{N}\left(\mathrm{sp}^{2}\right)$ single $(1.40 \AA)$ and $\mathrm{C}\left(\mathrm{sp}^{2}\right)=\mathrm{N}\left(\mathrm{sp}^{2}\right)$ double bond length $(1.29 \AA),{ }^{21}$ which indicates some evidence for $\mathrm{C}=\mathrm{N}$ tautomerism.

Interestingly in none of the studied compounds any evidence for form a in Scheme 4 was detected in the solid state. Another remarkable aspect of the amines 1-3 is the option to form different stable $\mathrm{N}-\mathrm{H} \cdots \mathrm{N}$ bonded aggregates (Table 2). ${ }^{22}$

Table 1 Selected bond lengths $(\AA)$ and angles $\left({ }^{\circ}\right)$ for compounds 1-6

\begin{tabular}{llll}
\hline Amines & $\mathbf{1}$ & 2 (av.) & 3 (av.) \\
\hline C1-N1' & $1.336(4)$ & $1.374(2)$ & $1.363(3)$ \\
C8-N1' & $1.367(4)$ & $1.370(2)$ & $1.365(2)$ \\
C1-N1 & $1.331(4)$ & $1.293(2)$ & $1.292(2)$ \\
C8-N2 & $1.301(4)$ & $1.307(2)$ & $1.301(2)$ \\
C1-N1'-C8 & $120.3(2)$ & $124.89(14)$ & $125.59(17)$ \\
\hline Amides & $\mathbf{4}($ av.) & $\mathbf{5}$ & 6 \\
\hline C1-N1' & $1.337(3)$ & $1.332(2)$ & $1.366(3)$ \\
C8-N1' & $1.342(3)$ & $1.331(2)$ & $1.365(3)$ \\
C1-N1 & $1.339(3)$ & $1.341(2)$ & $1.334(3)$ \\
C8-N2 & $1.323(3)$ & $1.344(2)$ & $1.328(3)$ \\
Al1-N1 & $1.929(2)$ & $1.956(1)$ & $1.995(2)$ \\
Al1-N2 & $1.927(2)$ & $1.967(1)$ & $1.996(2)$ \\
Al2-N1' & - & - & $2.066(2)$ \\
C1-N1'-C8 & $119.42(19)$ & $122.97(12)$ & $118.44(18)$ \\
N1-Al1-N2 & $91.32(8)$ & $96.52(5)$ & $87.75(8)$
\end{tabular}

Table 2 Hydrogen bonding properties of 1-3

\begin{tabular}{llll}
\hline & 1 & 2 (av.) & 3 (av.) \\
\hline $\mathrm{H} 11^{\prime} \cdots \mathrm{N} 1(\AA)$ & $2.15(5)$ & $2.08(2)$ & $2.12(2)$ \\
$\mathrm{H} 1 \cdots \mathrm{N} 1^{\prime}(\AA)$ & $2.15(5)$ & - & - \\
$\mathrm{N} 1 \cdots \mathrm{N} 1^{\prime}(\AA)$ & $2.910(4)$ & $2.920(2)$ & $2.926(2)$ \\
$\mathrm{N} 1^{\prime}-\mathrm{H} 1^{\prime} \cdots \mathrm{N} 1\left(^{\circ}\right)$ & $167(5)$ & $171.5(2)$ & $161(2)$ \\
$\mathrm{N} 1-\mathrm{H} 1 \cdots \mathrm{N} 1^{\prime}\left({ }^{\circ}\right)$ & $177(6)$ & - & -
\end{tabular}


Starting with bis-(benzothiazol-2-yl)-amine 1 (Fig. 2) infinite chains of the molecules can be observed because each molecule forms two hydrogen bonds to two neighbours. In any case the bridging $\mathrm{N} 1^{\prime}$ of one molecule and the ring nitrogen atom N1 of another form a suitable hydrogen donor-acceptor pair. Due to the positional disorder of the $\mathrm{NH}$ hydrogen atom two hydrogen bridges are feasible: either $\mathrm{N} 1-\mathrm{H} 1 \cdots \mathrm{N} 1^{\prime}$ or $\mathrm{N} 1^{\prime}-\mathrm{H} 1^{\prime} \cdots \mathrm{N} 1$.

The amine hydrogen atom can easily be switched among $\mathrm{N} 1$ and N1' because of the rather short intramolecular N1/N1' distance $(2.910 \AA)$ and the chain-like formation of hydrogen bridged aggregates.

Focusing on the ligand bis-(4-methylbenzothiazol-2-yl)amine 2 (Fig. 3), which differs from 1 just by the two additional methyl groups, also hydrogen bonding can be observed. The substitution prunes the aggregation to discrete dimers, only N1' acting as a hydrogen donor, because in 2 and 3 the amine $\mathrm{H}$-atom is exclusively located at the bridging position. Consequently the ring nitrogen atom N1 of the cisaligned 4-methylbenzothiazole unit acts as the corresponding hydrogen acceptor of the adjacent molecule. Even the related $\mathrm{CH}_{2}$ linked ligand system $\left(4-\mathrm{MeNCOC}_{6} \mathrm{H}_{4}\right)_{2}$ reveals the presence of $\mathrm{C}-\mathrm{H} \cdots \mathrm{N}$ hydrogen bonds, in which the bridging methylene moiety is acting as hydrogen donor to form a $3 \mathrm{D}$ network. The strongest hydrogen bond interactions within the solid state structure of $\left(4-\mathrm{MeNCOC}_{6} \mathrm{H}_{4}\right)_{2}$ result in a $\mathrm{C}-\mathrm{H} \cdots \mathrm{N}$ angle of $171.1^{\circ}$ and a $\mathrm{H} \cdots \mathrm{N}$ distance of $2.39 \AA^{6 a}$

Complementary to the abovementioned ligand the bis-(4methoxybenzothiazol-2-yl)-amine 3 shows methoxy residues instead of simple methyl groups in 2. Again, a different aggregation in the solid state is present since compound 3 forms a tetrameric hydrogen bonded species (Fig. 4). Within this motif also only $\mathrm{N} 1$ ' acts as the hydrogen donor. Remarkably the methoxy oxygen atoms are not involved in any hydrogen bonding. Although 3 forms two intermolecular hydrogen bonds with two other molecules like in 1, it does not generate infinite chains but forms a discrete tetramer. This is due to the fact that both adjacent hydrogen bonded molecules are additionally coordinated by another amine for their part, so that four amine derivatives are ordered in a cyclic fashion. In contrast to the other ligand systems this arrangement of hydrogen bonds in 3 is not as favoured as in the other cases, which is confirmed by the disadvantageous $\mathrm{D}-\mathrm{H} \cdots \mathrm{A}$ angle and the long $\mathrm{H} \cdots$ A distance (Table 2).

\section{Syntheses of the aluminium complexes}

Analogue to the procedure described earlier for metallated bisheterocyclo methanides like $\left[\mathrm{Me}_{2} \mathrm{Al}\left\{\left(\mathrm{NCOC}_{6} \mathrm{H}_{4}\right)_{2} \mathrm{CH}\right\}\right]^{6 b}$ or $\left[\mathrm{Me}_{2} \mathrm{Al}\left\{\right.\right.$ Dipp $_{2}$ nacnac $\left.\}\right],{ }^{23}$ the amines 1-3 were treated with a slight excess of pure trimethyl aluminium at about $0{ }^{\circ} \mathrm{C}$, dissolved in toluene (Scheme 5). After slow addition of the organometallic reagent the reaction mixture was allowed to warm to room temperature and kept stirring over night for optimised conversion.

Three different bis-heterocyclo amides containing an $\mathrm{AlMe}_{2}$ unit could be synthesised in moderate yields. Scheme 5 shows

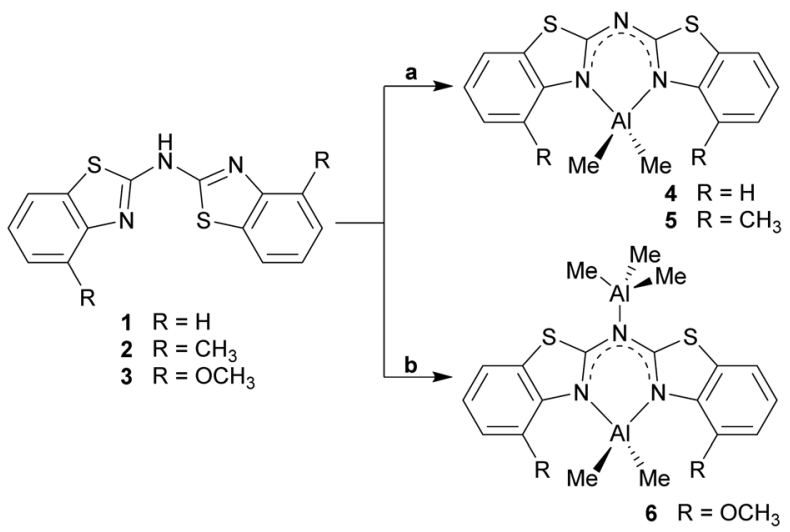

Scheme 5 Synthesis of the dimethyl aluminium containing compounds 4-6 (toluene, $0^{\circ} \mathrm{C}$; a: 1.1 eq. $\mathrm{AlMe}_{3} ; \mathrm{b}$ : exc. $\mathrm{AlMe}_{3}$ ).

the reaction of the starting materials with one equivalent $\mathrm{AlMe}_{3}$ to give the monoanionic amide chelating the dimethyl aluminium moiety and with the second equivalent an additionally $\mathrm{AlMe}_{3}$ molecule to be co-coordinated by the bridging amide nitrogen atom. Apart from NMR spectroscopic characterisation in solution also X-ray structure determination was applied to the received single crystals.

\section{Structural comparison of 4-6}

At first glance the crystal structures of all three metallated species look almost the same except for the additional $\mathrm{AlMe}_{3}$ coordination in $\mathbf{6}$. The asymmetric unit of $\mathbf{4}$ contains two molecules, in 5 just one and in 7 one target molecule and a lattice toluene molecule. In all cases the amine functionality is deprotonated and the organometallic $\mathrm{AlMe}_{2}$ residue in each case is coordinated by the two ring nitrogen donor atoms N1/ $\mathrm{N} 2$ within the two benzothiazole rings. This chelating ability is comparable to that of the bis-heterocyclo methanides, where formally the bridging nitrogen atom is iso-valence-electronically replaced by a $\mathrm{CH}$-group. ${ }^{6}$ The main difference of 4-6 (Fig. 5-7) and the corresponding methanides equipped with benzoxazole or benzothiazole moieties is, that rather than the

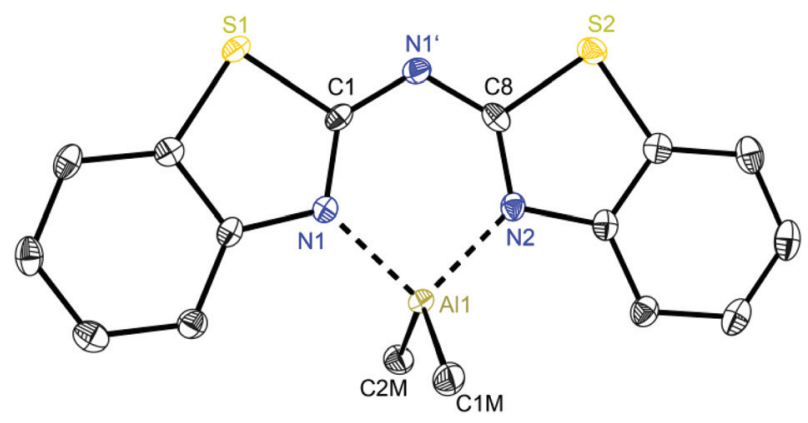

Fig. 5 Molecular structure of one molecule of $\left[\mathrm{Me}_{2} \mathrm{Al}\left\{\left(\mathrm{NCSC}_{6} \mathrm{H}_{4}\right)_{2} \mathrm{~N}\right\}\right]$ (4). Anisotropic displacement parameters are depicted at the $50 \%$ probability level. Hydrogen atoms and positional disorder of the whole molecule are omitted for clarity. Structural data are given in Tables 1 and 3. 


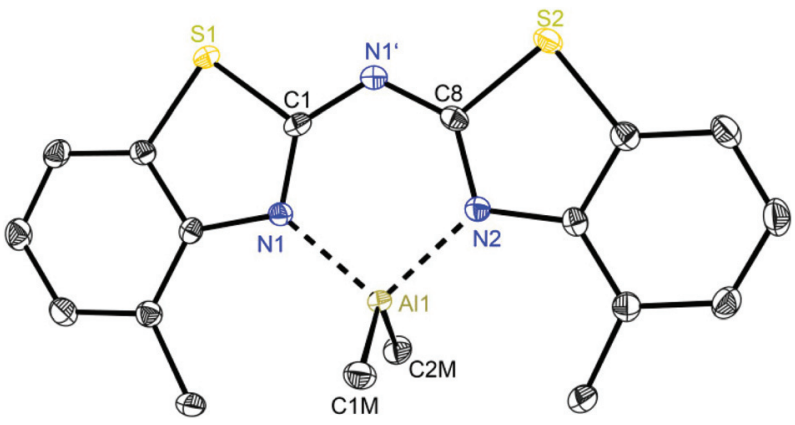

Fig. 6 Molecular structure of $\left[\mathrm{Me}_{2} \mathrm{Al}\left\{\left(4-\mathrm{MeNCSC}_{6} \mathrm{H}_{3}\right)_{2} \mathrm{~N}\right\}\right]$ (5). Anisotropic displacement parameters are depicted at the $50 \%$ probability level. Hydrogen atoms are omitted for clarity. Structural data are given in Tables 1 and 3.

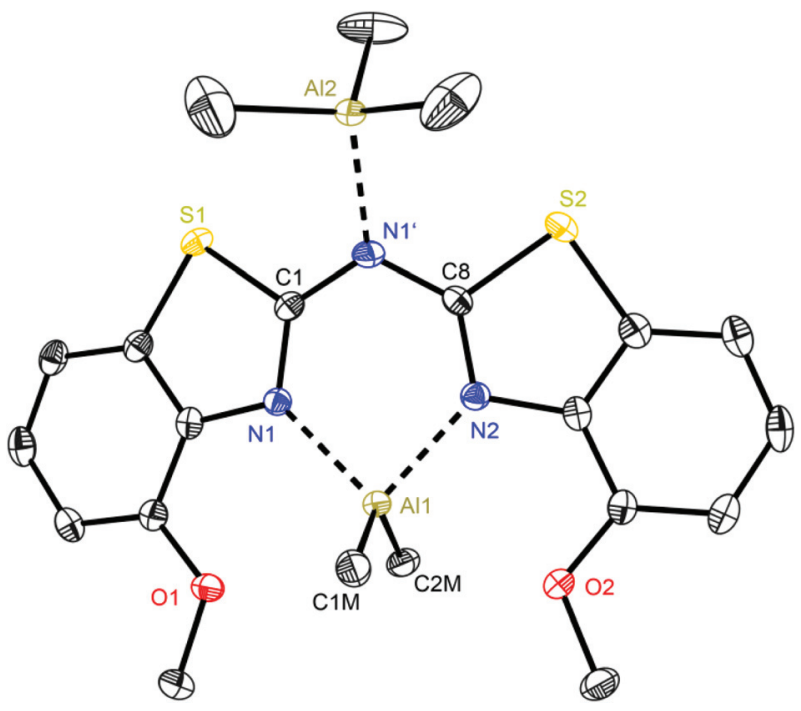

Fig. 7 Molecular structure of $\left[\mathrm{Me}_{2} \mathrm{Al}\left\{\left(4-\mathrm{OMeNCSC}_{6} \mathrm{H}_{3}\right)_{2} \mathrm{~N}\right\} \cdot \mathrm{AlMe}_{3}\right]$ (6). Anisotropic displacement parameters are depicted at the $50 \%$ probability level. Co-crystallised solvent molecules, hydrogen atoms and positional disorder of the whole molecule are omitted for clarity. Structural data are given in Tables 1 and 3 .

amide atom no further involvement of the bridging $\mathrm{CH}-$ functionality in coordination was observed yet. Just one example of this kind of coordination motif was obtained by synthesis of $\left[\operatorname{MeZn}\left\{(\mathrm{Py})_{2} \mathrm{CH}\right\}\right]_{2}, \mathrm{Py}=$ pyrid-2-yl. In that dimeric structure the organozinc part is chelated by two ring nitrogen atoms of one ligand as well as coordinated by the bridging carbon atom of the second half of the head-to-tail dimer. ${ }^{24}$ With compound 6 it was also possible to generate an additional binding site for another metal. This is very advantageous in respect to the Janus head ligands or scorpionates, which offer two different coordination sites and facilitate homo- or heterobimetallic complexes as well. ${ }^{5 a-c, e, 25}$

In consideration of some paradigmatic bond lengths and angles within the formed six-membered metalla heterocycles, which are displayed in Table 1 , some concluding statements can be made:

- From comparison 4 to 5 it is evident, that the $\mathrm{C}-\mathrm{N}$ bond lengths within the metalla heterocycle cover the narrow range of 1.323 to $1.342 \AA$ for $\mathbf{4}$ and 1.331 to $1.344 \AA$ for $\mathbf{5}$.

- The angle in the backbone of the deprotonated ligand system as well as the bite angle of the chelating nitrogen atoms and the aluminium fragment are widened from 4 $\left(119.42^{\circ}\right.$ and $\left.91.32^{\circ}\right)$ to $5\left(122.97^{\circ}\right.$ and $\left.96.52^{\circ}\right)$.

- The deviation of the metal atom from the $\mathrm{C}_{2} \mathrm{~N}_{3}$ main ligand plane, the folding as well as the torsion angles are decreasing from 4 to 5, indicating that the bis-(4-methylbenzothiazol-2-yl)-amide 5 is most suitable for close coordination of an $\mathrm{Al}($ III) cation (Table 3). According to this also the bis-heterocyclo methanide derivative with additional methyl substituents $\left[\left(4-\mathrm{MeNCOC}_{6} \mathrm{H}_{4}\right)_{2} \mathrm{CH}\right]^{-}$shows a distinct coordination preference for $\mathrm{Al}(\mathrm{III})$, which is displayed in a small folding angle (3.04 to $4.43^{\circ}$ ) and just slight deviations of the metal atom from the $\mathrm{C}_{3} \mathrm{~N}_{2}$ plane (0.009 to $0.048 \AA$ ) observed for a series of corresponding aluminium complexes. ${ }^{6 a}$

With regard to the crystal structure of $\mathbf{6}$ several different features have to be considered in addition to the already stated. On the one hand this is a unique structure within the bis(benzothiazol-2-yl)-methanide and -amide complexes, which contains a second Lewis acidic $\mathrm{AlMe}_{3}$ fragment. However, this motif of an additional Lewis acid base adduct formation was also noticed in $\left[\mathrm{Et}_{2} \mathrm{Al}\left\{(\mathrm{Py})_{2} \mathrm{~N}\right\} \cdot \mathrm{AlEt}_{3}\right]$ from previous work. ${ }^{4 b}$

This additional coordination causes special properties referring to the folding parameters and the bonding situation. The resulting six-membered metalla heterocycle deviates most from the other structures $\mathbf{4}$ and $\mathbf{5}$ and the isoelectronic methanide equivalents. ${ }^{6 b}$ The lengths of the bridging $\mathrm{C}_{i p s o}-\mathrm{N}_{\text {bridge }}$ bonds stay nearly the same upon metallation (1.363(3) and 1.365(2) $\AA$ in the protonated ligand 3 vs. 1.366(3) and 1.365(3) $\AA$ in 6), whereas the endocyclic $\mathrm{C}_{i p s o}-\mathrm{N}_{\text {het }}$ bond lengths are elongated (Table 1) due to the loss of electron density by coordination of the electrophilic $\mathrm{AlMe}_{2}{ }^{+}$cation. By introducing the methoxy moieties to the ligand framework the bite angle of the chelating site N1-Al1-N2 shrinks to $87.8^{\circ}$ and as a consequence the Al-N distances are elongated to 1.995(2) $\AA$ and

Table 3 Folding parameters for 1-6

\begin{tabular}{lllr}
\hline & $\begin{array}{l}\text { Metal dist. from } \\
\mathrm{C}_{2} \mathrm{~N}_{3} \text { plane }(\AA)\end{array}$ & $\begin{array}{l}\text { Folding } \\
\text { angle }\left(^{\circ}\right)\end{array}$ & $\begin{array}{r}\text { Torsion } \\
\text { angle }\left({ }^{\circ}\right)\end{array}$ \\
\hline $\mathbf{1}$ & - & $1.18(10)$ & $175.1(8)$ \\
$\mathbf{2}$ & - & $3.11(6)$ & $172.0(4)$ \\
$\mathbf{3}$ & - & $5.76(7)$ & $175.0(5)$ \\
$\mathbf{4}$ & $0.100(2)$ & $7.58(17)$ & $6.4(6)$ \\
$\mathbf{5}$ & $0.038(2)$ & $6.34(4)$ & $0.9(4)$ \\
$\mathbf{6}$ & $0.158(3)^{a}$ & $25.46(5)$ & $0.6(7)$
\end{tabular}

${ }^{a}$ Deviation from the N1-C1-C8-N2 plane. The extent of folding is calculated by measuring the angle between the planes, which are spanned by each heteroaromatic substituent including the amide bridge, and the overall torsion angle is distinguished by the averaged sum of the single torsion angles N1-C1-N1'-C8 and $\mathrm{C} 1-\mathrm{N} 1{ }^{\prime}-\mathrm{C} 8-\mathrm{N} 2$. 
among the longest observed in this series of group 13 complexes.

On the other hand it is noticeable, that the central six-membered metalla heterocycle differs most from planarity when compared to 4 and $\mathbf{5}$. The bridging nitrogen atom $\mathrm{N}^{\prime}$ is no longer located within the plane made up from N1, C1, C8 and $\mathrm{N} 2$ like in the other structures. N1' and Al1 are displaced from the $\mathrm{C}_{2} \mathrm{~N}_{2}$ plane to the same side, whereby even the deviation from that plane is more pronounced for $\mathrm{N}^{\prime}$ than for Al1 (0.0211(3) vs. $0.0158(3) \AA)$ to result in a pronounced butterflyarrangement like in the comparable crystal structure of $\left[\mathrm{Et}_{2} \mathrm{Al}\left\{(\mathrm{Py})_{2} \mathrm{~N}\right\} \cdot \mathrm{AlEt}_{3}\right]^{4 b}$ The $\mathrm{C} 1-\mathrm{N} 1$ and $\mathrm{C} 8-\mathrm{N} 2$ bonds are almost aligned parallel, resulting in a torsion angle of only $0.5^{\circ}$, but the folding of the whole framework, which is also indicated by the large displacement of the bridging amide functionality, is very distinct (about $25.5^{\circ}$, Table 3 ).

These findings confirm the assumption, that the lone pair generated by deprotonation of the parent ligand is not fully delocalised among the other $\mathrm{C}-\mathrm{N}$ bonds but rather predominantly localised at the central nitrogen atom N1'. This amidic resonance structure a in Scheme 6 seems to suit best this binding situation, because the amide anion is similar to the carbanion $\mathrm{sp}^{3}$-hybridised ${ }^{26}$ and there is an obvious difference between the bond lengths concerning the endocyclic and exocyclic $\mathrm{C}-\mathrm{N}$ bonds, whereat the latter are significantly elongated.

The referring ${ }^{1} \mathrm{H}-\mathrm{NMR}$ data of 6 show also the presence of the $\mathrm{AlMe}_{2}$ fragment and the additional $\mathrm{AlMe}_{3}$ Lewis acidic group. Furthermore, the apparent cross peak for the ${ }^{3} J$-coupling between the protons of the $\mathrm{AlMe}_{2}$ unit and $\mathrm{N} 1$ from an ${ }^{1} \mathrm{H}-{ }^{15} \mathrm{~N}-\mathrm{HMBC}$ NMR experiment proves, that the $\mathrm{AlMe}_{2}$ unit is still coordinated by the chelating endocyclic nitrogen donors in solution. The same is valid for the observed ${ }^{4} \mathrm{~J}$-coupling between the aromatic $\mathrm{H} 5$ and the same nitrogen donor. Those cross peaks were also detected in the case of the corresponding methanide derivatives. ${ }^{6 b}$ However, no interaction of the $\mathrm{AlMe}_{3}$ towards the bridging $\mathrm{N1}^{\prime}$ ' was detected suggesting that the Lewis acid base adduct $\mathbf{6}$ is not maintained in solution.
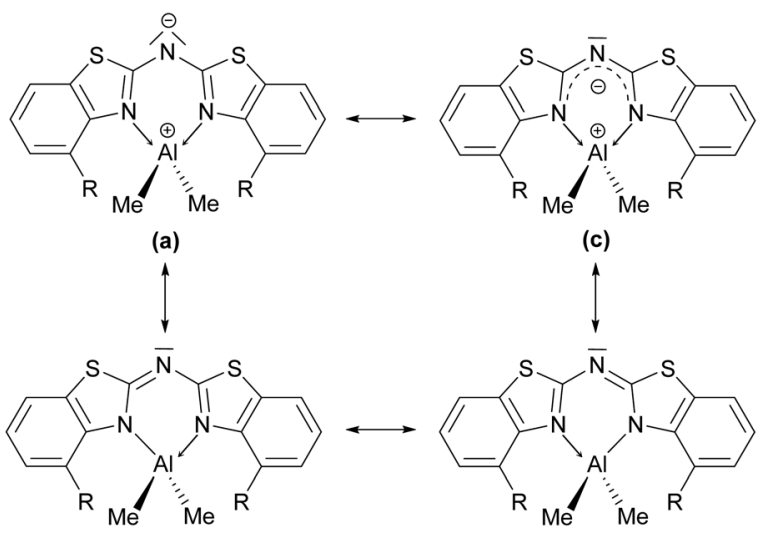

(b)

Scheme 6 Mesomeric resonance structures of group 13 bis-(benzothiazol-2-yl)-amides 4-6.

\section{Lithiated species}

As depicted in Scheme 7 the lithiation of the parent ligand system bis-(4-methylbenzothiazol-2-yl)-amine 2 in the absence of Lewis-bases leads to the formation of a tetrameric species. The lithium cations in the centre of $\mathbf{8}$ are arranged in a distorted tetrahedral fashion, where the distance between the two opposite perpendicularly aligned $\mathrm{Li}$... Li edges is considerably elongated. Because of the limited crystal quality of $\mathbf{8}$ the geometrical features are not discussed in any detail but only presented in a qualitative manner. For 7 no suitable crystals for X-ray diffraction could be obtained, but this species could sufficiently be characterised and identified in solution by NMR spectroscopic techniques.

Due to the limited solubility of the lithiated compounds in non-donating solvents and for a better comparability of the recorded NMR data deuterated THF was used as appropriate solvent. Presumably this courses the deaggregation of the tetramer 8 in solution, which was obtained upon recrystallisation from non-donating toluene.

The crystal structure permits to discuss the binding motif in this lithiated species. Interestingly in contrast to all other metallated species 4-6 and the compounds in earlier investigations of the related bis-heterocyclomethanides ${ }^{6 b}$ the ligand in 8 has switched to the cis-cis configuration (see also Schemes 3 and 8). In all other cases the trans-trans isomer was favoured for the coordination of the $\mathrm{AlMe}_{2}$ moiety to the two nitrogen donor atoms of the heterocycles. The distorted $\mathrm{Li}_{4}$ tetrahedron ( $\mathrm{Li} \cdots \mathrm{Li}$ edges labelled from a-f in Fig. 8) is coordinated by four bis-(4-methylbenzothiazol-2-yl)-amide ligands (labelled from L1-L4), each containing three nitrogen atoms for coordination. The central, bridging nitrogen atoms of each ligand are pointing towards the centre of a $\mathrm{Li} \cdots \mathrm{Li}$ edge, so that over all four (a-d) of the six tetrahedral edges are coordinated (indicated in Fig. 8 as turquoise dashed lines) by one central nitrogen donor atom. The remaining two opposite long edges $\mathbf{e}$ and $\mathbf{f}$ are addressed by the nitrogen atoms in the periphery of the ligands $\mathbf{L} 3$ and L4. No coordination via the sulfur atoms in the backbone is observed.

Apart from the coordination of the $\mathrm{Li} \cdots \mathrm{Li}$ edges also the apical lithium cations are addressed by the cis-arranged nitrogen donors of the peripheral benzothiazole rings to gain fourfold coordination (grey dashed lines).

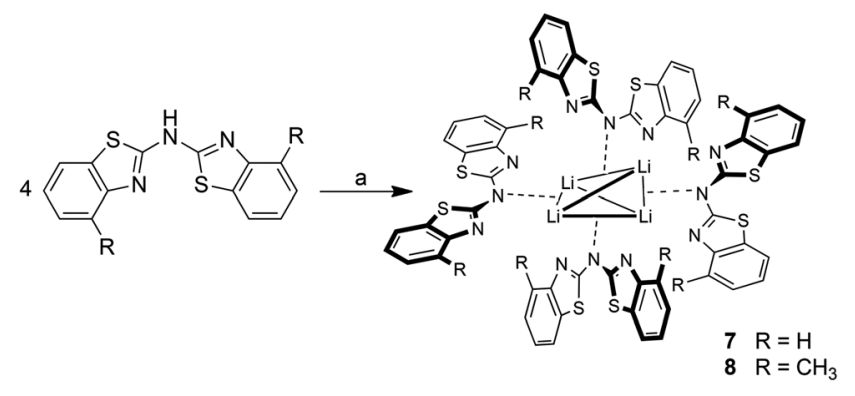

Scheme 7 Synthesis of the lithiated compounds 7-8 (a: 4.4 eq. nBuLi, toluene, $0^{\circ} \mathrm{C}$ ). 


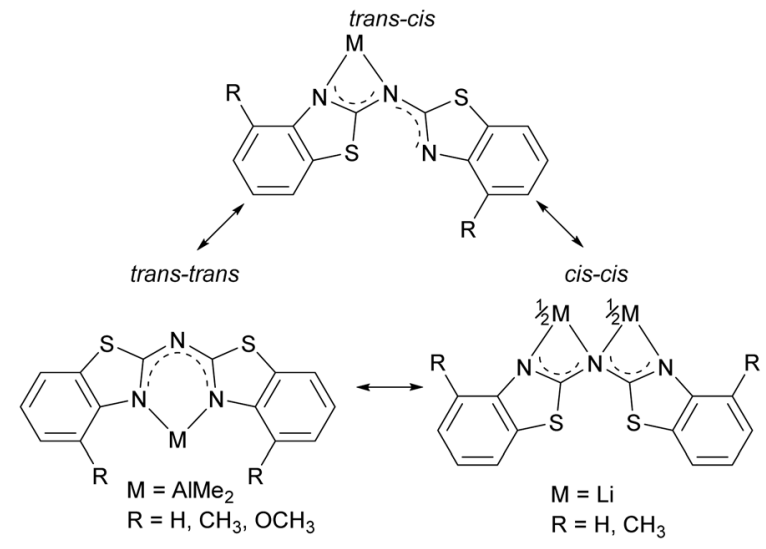

Scheme 8 Possible binding motifs upon metallation within 4-8.

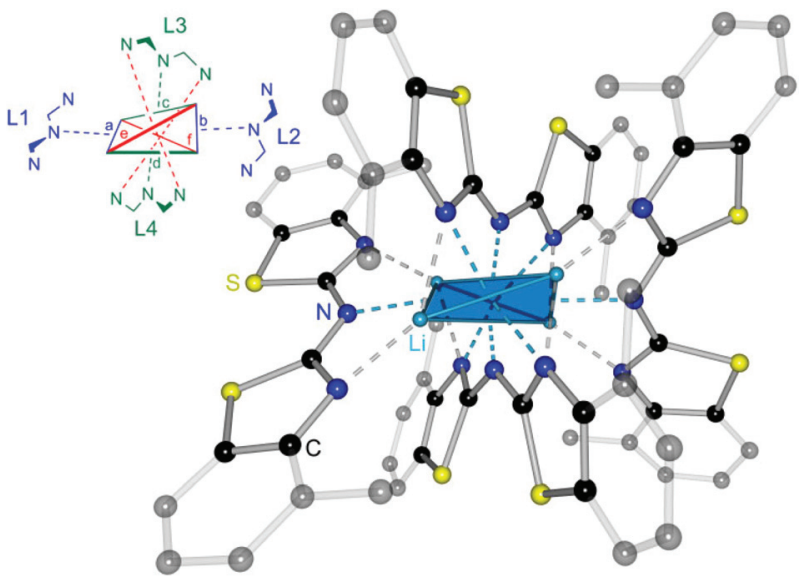

Fig. 8 Molecular structure of $\left[\mathrm{Li}\left\{\left(4-\mathrm{MeNCSC}_{6} \mathrm{H}_{3}\right)_{2} \mathrm{~N}\right\}\right]_{4}$ (8). To clarify the binding motif co-crystallised solvent molecules and hydrogen atoms are omitted as well as the annulated moieties are represented in faded colour. In the upper left corner a simplified model of the coordination environment is depicted.

The ligands $\mathbf{L 1}$ and $\mathbf{L} 2$ show the same coordination behaviour, whereas the central nitrogen atoms are pointing towards the edges $\mathbf{a}$ and $\mathbf{b}$, respectively, the neighbouring nitrogen atoms in the heterocycle are pointing to the lithium corners of the same edge. $\mathbf{L 3}$ and $\mathbf{L} 4$ however, show a different binding motif.

Each central amide moiety also points to the edges $\mathbf{c}$ and $\mathbf{d}$, respectively, but the geminal bonded nitrogen donors are oriented to the centres of the other edges $\mathbf{e}$ and $\mathbf{f}$. In these cases the thiazole units bridge equally between the edges as well as one of those corners.

So each edge is coordinated by at least one bridging amide (a-d) or two thiazole nitrogen atoms (e and f) and the corners are addressed each by two thiazole nitrogen atoms (one from $\mathbf{L} 1$ or $\mathbf{L} 2$ and the other one from $\mathbf{L} 3$ or $\mathbf{L 4}$ ).

A short comparison to other wide-spread $\mathrm{Li}_{4}$-tetrahedra containing organolithiums ${ }^{27}$ like $[\mathrm{EtLi}]_{4},{ }^{28}[\mathrm{MeLi}]_{4}{ }^{29}$ or $[t \text {-BuLi }]_{4}{ }^{30}$ or to lithium amide rings and ladders ${ }^{31}$ shows, that in 8 a highly distorted $\mathrm{Li}_{4}$-tetrahedron instead of the expected ring stack or ladder is formed. In contrast to the abovementioned tetrahedra with quite regular $\mathrm{Li} \cdots \mathrm{Li}$ edges (averaged values: $[\text { EtLi }]_{4}: 2.53 \AA ̊$; $[\mathrm{MeLi}]_{4}: 2.59 \AA$; $[\text { t-BuLi }]_{4}: 2.41 \AA$ A) 8 exhibits four shorter $\mathrm{Li} \cdots \operatorname{Li}(2.71(1)$ to $3.00(1) \AA)$ and two elongated (3.48(1) to $4.13(1) \AA$ ) edges.

As depicted in Scheme 8 in total three different binding motifs can occur in the case of the metallated species 4-8. Comparing these motifs to the experimentally determined crystal structures the trans-trans conformation was mostly observed within in the row of the investigated amides as well as methanide derivatives and the cis-cis aligned ligand was just detected once by means of $\mathbf{8}$. In contrast to this the cistrans conformation shown at the left hand side could not be observed yet in any bis-(benzothiazol-2-yl)-amide and corresponding methanide. ${ }^{6 b}$ Instead the trans-trans conformation facilitates the formation of a six-membered metalla heterocycle in contrast to the cis-cis arrangement, where a higher strained four-membered ring would result. However, this cis-trans arrangement was present in the molecular structure of $\left[\mathrm{Me}_{2} \mathrm{Tl}\left\{(\mathrm{Py})_{2} \mathrm{~N}\right\}\right]_{\infty}$ due to the larger and easier to polarise cation. ${ }^{4 b, c}$

\section{Conclusions}

In summary, three neutral bis-heterocyclo amines 1-3 and the corresponding metal amides 4-8 could be synthesised and characterised by single crystal X-ray diffraction.

In contrast to the corresponding methane derivatives the amines 1-3 always form a co-planar arrangement of the heteroaromatic substituents preferentially in the cis-cis conformer with a torsion angle of almost $180^{\circ}$. Especially the formation of different hydrogen bonded aggregates helps to maintain this planarity. An overall comparison of the hydrogen bonding abilities of the investigated systems shows, that the steric demand of the substituent at the $\mathrm{C}_{6}$-perimeter has an increasing influence on the aggregation and the strength of the formed hydrogen bonds. While $\mathbf{1}$ with the smallest steric demand forms the most linear but also longest hydrogen bonds in a $2 \mathrm{D}$ chain-like aggregation motif, the implementation of methyl groups augments the steric demand of the ligand 2 compared to $\mathbf{1}$. This leads to the formation of a dimeric species, causing an almost linear $\mathrm{D}-\mathrm{H} \cdots \mathrm{A}$ angle and the shortest distances between the acceptor and the bridging hydrogen. Further increasing the steric congestion in 3 the methoxy groups force the molecule to divide its hydrogen bonding pattern between to two neighbouring molecules instead of just satisfying one in 2 .

The metallated species 4-5 are comparable to the related methanides with the nitrogen atoms of the benzothiazole units chelating in a trans-trans fashion to the $\mathrm{AlMe}_{2}$ moiety (Scheme 8). The experimentally determined values for the $\mathrm{C}-\mathrm{N}$ bond lengths suggest a delocalised six electron $\pi$-system, because they are half way between $\mathrm{C}\left(\mathrm{sp}^{2}\right)-\mathrm{N}\left(\mathrm{sp}^{2}\right)$ single $(1.40 \AA)$ and $\mathrm{C}\left(\mathrm{sp}^{2}\right)=\mathrm{N}\left(\mathrm{sp}^{2}\right)$ double bonds $(1.29 \AA)$. The widening of 
the backbone and the bite angle from 4-5 can be attributed to the additional strain introduced by the methyl groups in 5 which causes the benzothiazole units to bent away from each other. This evidence is mirrored by the transannular $\mathrm{N} 1 \cdots \mathrm{N} 2$ distance of 2.764(3) $\AA$ for 4 and 2.927(2) $\AA$ for 5 and by the $\mathrm{N} 1{ }^{\prime} \cdots \mathrm{Al} 1$ distance (4: 3.334(2) Å; 5: 3.250(2) A), illustrating the deeper inserted organometallic moiety in 5 compared to 4 .

The coordination of the bridging amide to an additional Lewis acid in terms of $\mathrm{Al} 2$ in 6 causes the whole ligand framework to fold and hence lowers the orbital overlap of the concerned $\pi$-system. This folding can be explained, since $\mathrm{N} 1^{\prime}$ is slightly inclined towards $\mathrm{Al} 2$. This distortion leads to an environment of $\mathrm{N} 1$ ', which is indicating a partially stereochemically active lone-pair at the nitrogen atom. The angular sum around $\mathrm{N} 1^{\prime}$ of about $359^{\circ}$ is marginally smaller than for an expected ideal $\mathrm{sp}^{2}$-hybridised nitrogen atom. For further applications of such metal complexes to generate low valent metal fragments the criterion of maximum orbital overlap is vital, because the tentative lone pair at $\mathrm{Al}(\mathrm{I})$ from the reduction of the $\mathrm{Al}(\mathrm{III})$ can best be stabilised by planar arranged ligand systems.

The lithiated compounds $\mathbf{7}$ and $\mathbf{8}$ are different in comparison to the group 13 complexes: by means of the crystal structure of 8 it was possible to determine the ligand arrangement also in the presence of a non-polar, aprotic solvent like toluene. A tetrameric metal complex is formed upon lithiation of 2 in the absence of any Lewis donor base, which shows a clear preference to promote a cis-cis configuration of the amide ligand, never observed in similar systems before. Due to the lack of other donors the active ligand periphery has to suite the lithium tetrahedron in the centre of the molecular structure of $\mathbf{8}$. As a consequence each available nitrogen donor site of the bis-heterocyclo amides has to be involved in coordination to provide the required electron density to lithium.

Moreover, in each molecular structure the metal coordination only involves the nitrogen atoms, no metal-sulfur interaction could be observed so far. Referring to the HSAB principle ${ }^{32}$ this fact was expected in this paper, because $\mathrm{Al}^{3+}$ and $\mathrm{Li}^{+}$cations are regarded hard cations and therefore preferentially coordinate the harder nitrogen rather than the soft sulfur atom.

\section{Experimental section}

\section{General procedures}

All manipulations were carried out under an atmosphere of $\mathrm{N}_{2}$ or Ar by using Schlenk techniques. ${ }^{33}$ All solvents used within metallation reactions were distilled from $\mathrm{Na}$ or $\mathrm{K}$ before use. The starting materials were purchased commercially und used as received. ${ }^{1} \mathrm{H},{ }^{13} \mathrm{C},{ }^{15} \mathrm{~N}$ and ${ }^{27} \mathrm{Al}$ NMR spectroscopic data were recorded on a Bruker Avance $500 \mathrm{MHz}$, Bruker Avance $400 \mathrm{MHz}$ and a Bruker Avance $300 \mathrm{MHz}$ spectrometer and referenced to the deuterated solvent $\left(\right.$ thf- $\left.\mathrm{d}_{8}\right) .{ }^{34}$ Elemental ana- lyses (C, H, N and S) were carried out on a Vario EL3 at the Mikroanalytisches Labor, Institut für Anorganische Chemie, University of Göttingen. Several compounds are containing lattice solvent confirmed by X-ray diffraction, because the crystals were grown in the mother liquor. As a result of drying these samples not the whole amount of incorporated lattice solvent could be removed, so that no solvent free compounds are yielded. The remaining solvent leads to slightly enhanced values in the elemental analyses for $\mathrm{C}$ and $\mathrm{H}$. All EI-MS spectra $(70 \mathrm{eV})$ were recorded on a Finnigan MAT 95.

\section{Ligand syntheses}

In general the four different ligand systems were synthesised by coupling of two equivalents of 1-amino-benzoxazole respectively the corresponding C4-substituted 1-amino-benzothiazoles in the presence of phenol.

$\left(\mathbf{N C S C}_{6} \mathbf{H}_{4}\right)_{2} \mathbf{N H}$ (1). A mixture of 1-aminobenzothiazol (7.51 g, $50.0 \mathrm{mmol}, 2.0$ eq.) and phenol (3.13 g, $33.0 \mathrm{mmol}, 1.4$ eq.) was heated to $50{ }^{\circ} \mathrm{C}$ until a homogenous solution upon melting phenol was formed. Subsequently the reaction mixture was heated to reflux for $24 \mathrm{~h}$, after cooling to $\mathrm{rt}$ ethanol $(12.8 \mathrm{~mL})$ was added in one portion to the solidified reaction mixture und was boiled to reflux for an additional hour. The resulting dark blue slurry was again cooled to rt, stirred overnight, filtered off, washed with ethanol $(2 \times 5 \mathrm{~mL})$ and dried under reduced pressure. A dark blue powder was obtained in a yield of $2.58 \mathrm{~g}$ (9.10 mmol, 36\%). Crystals suitable for X-ray diffraction experiments could be obtained upon recrystallisation from toluene. Anal. Calcd for $\mathrm{C}_{14} \mathrm{H}_{9} \mathrm{~N}_{3} \mathrm{~S}_{2}$ (283.37 $\left.\mathrm{g} \mathrm{mol}^{-1}\right): \mathrm{C}, 59.34 ; \mathrm{H}, 3.20 ; \mathrm{N}, 14.83 ; \mathrm{S}, 22.63$. Found: C, 59.50; H, 3.38; N, 14.27; S, 21.70; $\delta^{1} \mathrm{H}(300 \mathrm{MHz}$, thf-d 8 ): $11.60(\mathrm{~s}, 1 \mathrm{H}, \mathrm{NH}), 7.75\left(\mathrm{~d},{ }^{3} \mathrm{~J}_{\mathrm{HH}}=7.8 \mathrm{~Hz}, 2 \mathrm{H}, \mathrm{H} 3\right), 7.62$ (d, $\left.{ }^{3} J_{\mathrm{HH}}=8.0 \mathrm{~Hz}, 2 \mathrm{H}, \mathrm{H} 6\right), 7.35\left(\mathrm{t},{ }^{3} J_{\mathrm{HH}}=7.7 \mathrm{~Hz}, 2 \mathrm{H}, \mathrm{H} 5\right), 7.19(\mathrm{t}$, $\left.{ }^{3} J_{\mathrm{HH}}=7.6 \mathrm{~Hz}, 2 \mathrm{H}, \mathrm{H} 4\right) ; \delta^{13} \mathrm{C}\left\{{ }^{1} \mathrm{H}\right\}(75 \mathrm{MHz}$, thf-d 8 ): $163.70(\mathrm{~s}, 2$ C, C1), 148.71 (s, 2 C, C7), 132.13 (s, 2 C, C2), 126.86 (s, 2 C, C5), 123.69 (s, 2 C, C4), 122.25 (s, 2 C, C3), 119.14 (s, 2 C, C6); EI-MS, $m / z$ (\%): 283 (100) $[\mathrm{M}]^{+}$.

$\left(4-\mathrm{MeNCSC}_{6} \mathrm{H}_{3}\right)_{2} \mathrm{NH}$ (2). A mixture of 1-amino-4-methylbenzothiazol (8.21 g, $50.0 \mathrm{mmol}, 2.0 \mathrm{eq}$.) and phenol (3.13 g, $33.0 \mathrm{mmol}, 1.4$ eq.) was heated to $50{ }^{\circ} \mathrm{C}$ until a homogenous solution upon melting phenol was formed. Subsequently the reaction mixture was heated to reflux for $24 \mathrm{~h}$, after cooling to rt ethanol $(12.8 \mathrm{~mL})$ was added in one portion to the solidified reaction mixture und was boiled to reflux for an additional hour. The resulting grey slurry was again cooled to rt, stirred overnight, filtered off, washed with ethanol $(2 \times 5 \mathrm{~mL})$ and dried under reduced pressure. A grey powder was obtained in a yield of $2.98 \mathrm{~g}$ (9.56 mmol, 38\%). Crystals suitable for X-ray diffraction experiments could be obtained upon recrystallisation from toluene. Anal. Calcd for $\mathrm{C}_{16} \mathrm{H}_{13} \mathrm{~N}_{3} \mathrm{~S}_{2}\left(311.42 \mathrm{~g} \mathrm{~mol}^{-1}\right)$ : $\mathrm{C}, 61.71 ; \mathrm{H}, 4.21 ; \mathrm{N}, 13.49 ; \mathrm{S}, 20.59$. Found: C, 63.61; $\mathrm{H}, 4.33 ; \mathrm{N}, 12.51 ; \mathrm{S}, 19.04$ (deviation due to remaining toluene); $\delta^{1} \mathrm{H}\left(300 \mathrm{MHz}\right.$, thf-d $\left._{8}\right): 11.51$ (s, $\left.1 \mathrm{H}, \mathrm{NH}\right), 7.59$ (d, $\left.{ }^{3} J_{\mathrm{HH}}=7.7 \mathrm{~Hz}, 2 \mathrm{H}, \mathrm{H} 3\right), 7.18\left(\mathrm{~d},{ }^{3} J_{\mathrm{HH}}=7.3 \mathrm{~Hz}, 2 \mathrm{H}, \mathrm{H} 5\right), 7.10(\mathrm{t}$, $\left.{ }^{3} J_{\mathrm{HH}}=7.6 \mathrm{~Hz}, 2 \mathrm{H}, \mathrm{H} 4\right), 2.64(\mathrm{~s}, 6 \mathrm{H}, \mathrm{H} 15) ; \delta^{13} \mathrm{C}\left\{{ }^{1} \mathrm{H}\right\}(75 \mathrm{MHz}$, 
Table 4 Crystal structure data for 1-6 and 8

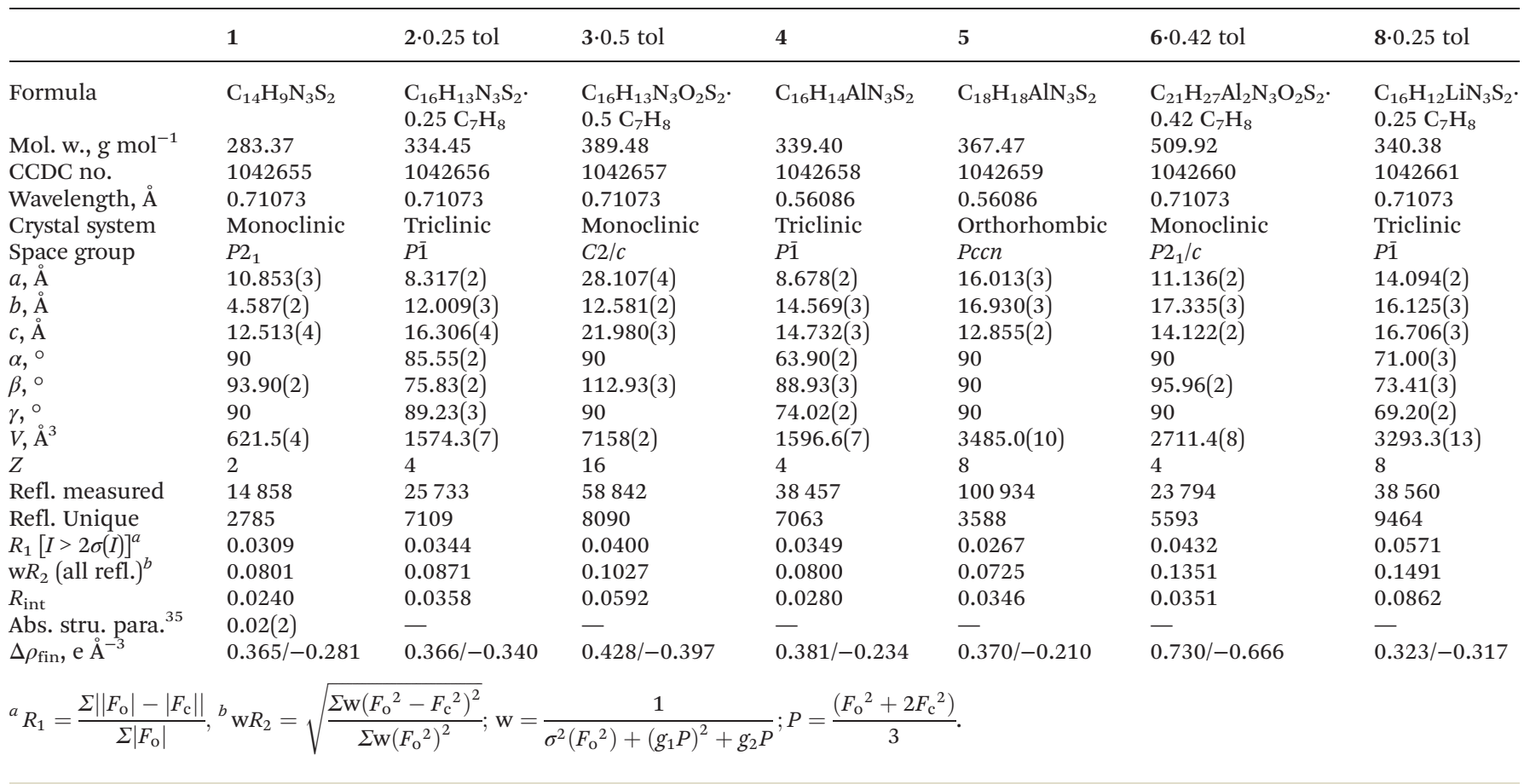

thf- $\mathrm{d}_{8}$ ): 161.77 (s, 2 C, C1), 148.71 (s, 2 C, C7), 132.04 (s, 2 C, C2), 129.52 (s, 2 C, C6), 127.50 (s, 2 C, C5), 123.67 (s, 2 C, C4), 119.53 (s, 2 C, C3), 18.38 (s, 2 C, C15); EI-MS, m/z (\%): 311 (100) $[\mathrm{M}]^{+}$.

(4-OMeNCSC $\left.6 \mathrm{H}_{3}\right)_{2} \mathbf{N H}$ (3). A mixture of 1-amino-4-methoxybenzothiazol (5.38 g, $29.9 \mathrm{mmol}, 2.0$ eq.) and phenol (1.97 g, $20.9 \mathrm{mmol}, 1.4$ eq.) was heated to $50{ }^{\circ} \mathrm{C}$ until a homogenous solution upon melting phenol was formed. Subsequently the reaction mixture was heated to reflux for $24 \mathrm{~h}$, after cooling to rt ethanol $(11.4 \mathrm{~mL})$ was added in one portion to the solidified reaction mixture und was boiled to reflux for an additional hour. The resulting brown slurry was again cooled to rt, stirred overnight, filtered off, washed with ethanol $(2 \times 5 \mathrm{~mL})$ and dried under reduced pressure. A brown powder was obtained in a yield of $693 \mathrm{mg}$ (2.02 mmol, 13\%, not optimised). Crystals suitable for X-ray diffraction experiments could be obtained upon recrystallisation from toluene. Anal. Calcd for $\mathrm{C}_{16} \mathrm{H}_{13} \mathrm{~N}_{3} \mathrm{O}_{2} \mathrm{~S}_{2}\left(343.42 \mathrm{~g} \mathrm{~mol}^{-1}\right)$ : C, 55.96; H, 3.82; N, 12.24; $\mathrm{S}$, 18.67. Found: C, 57.58; H, 4.08; N, 11.24 (deviation due to remaining toluene); $\delta^{1} \mathrm{H}\left(300 \mathrm{MHz}\right.$, thf- $\left.\mathrm{d}_{8}\right): 11.69(\mathrm{~s}, 1 \mathrm{H}, \mathrm{NH})$, $7.30\left(\mathrm{~d},{ }^{3} J_{\mathrm{HH}}=7.8 \mathrm{~Hz}, 2 \mathrm{H}, \mathrm{H} 5\right), 7.11\left(\mathrm{~d},{ }^{3} J_{\mathrm{HH}}=7.9 \mathrm{~Hz}, 2 \mathrm{H}\right.$, H4), $6.92\left(\mathrm{~d},{ }^{3} J_{\mathrm{HH}}=7.9 \mathrm{~Hz}, 2 \mathrm{H}, \mathrm{H} 3\right), 4.02(\mathrm{~s}, 6 \mathrm{H}, \mathrm{H} 15) ; \delta^{13} \mathrm{C}$ $\left\{{ }^{1} \mathrm{H}\right\}$ (75 MHz, thf-d ${ }_{8}$ ): 164.28 (s, 2 C, C1), 150.80 (s, 2 C, C6), 136.82 (s, 2 C, C7), 132.82 (s, 2 C, C2), 124.15 (s, 2 C, C4), 114.58 (s, 2 C, C5), 109.43 (s, 2 C, C3), 56.74 (s, 2 C, C15); EI-MS, $m / z(\%): 343$ (100) $[\mathrm{M}]^{+}$.

$\left(\mathrm{NCOC}_{6} \mathbf{H}_{4}\right)_{2} \mathbf{N H}(9)$. A mixture of 1-aminobenzoxazol (5.11 g, 38.1 mmol, 2.0 eq.) and phenol (2.51 g, $26.7 \mathrm{mmol}, 1.4$ eq.) was heated to $50{ }^{\circ} \mathrm{C}$ until a homogenous solution upon melting phenol was formed. Subsequently the reaction mixture was heated to reflux for $24 \mathrm{~h}$, after cooling to rt ethanol $(9.5 \mathrm{~mL})$ was added in one portion to the solidified reaction mixture und was boiled to reflux for an additional hour. The resulting pale grey slurry was again cooled to rt, stirred overnight, filtered off, washed with ethanol $(2 \times 5 \mathrm{~mL})$ and dried under reduced pressure. A pale grey powder was obtained in a yield of $152 \mathrm{mg}(0.60 \mathrm{mmol}, 3 \%)$. No crystals suitable for X-ray diffraction experiments could be obtained upon recrystallisation, neither from ethanol, acetone nor THF. Anal. Calcd for $\mathrm{C}_{14} \mathrm{H}_{9} \mathrm{~N}_{3} \mathrm{O}_{2}\left(251.25 \mathrm{~g} \mathrm{~mol}^{-1}\right)$ : C, 66.93; H, 3.61; $\mathrm{N}, 16.73$. Found: $\mathrm{C}, 66.44 ; \mathrm{H}, 3.56 ; \mathrm{N}, 16.73 ; \delta^{1} \mathrm{H}(300 \mathrm{MHz}$, DMSO-d $): 7.29$ (d, $\left.{ }^{3} J_{\mathrm{HH}}=4.5 \mathrm{~Hz}, 2 \mathrm{H}, \mathrm{H} 3\right), 7.27\left(\mathrm{~d},{ }^{3} \mathrm{~J}_{\mathrm{HH}}=5.1\right.$ $\mathrm{Hz}, 2 \mathrm{H}, \mathrm{H6}), 7.07\left(\mathrm{t},{ }^{3} J_{\mathrm{HH}}=7.6 \mathrm{~Hz}, 2 \mathrm{H}, \mathrm{H} 5\right), 6.95\left(\mathrm{t},{ }^{3} J_{\mathrm{HH}}=7.7\right.$ $\mathrm{Hz}, 2 \mathrm{H}, \mathrm{H} 4)$, NH not detected because of fast exchange with remaining water; $\delta^{13} \mathrm{C}\left\{{ }^{1} \mathrm{H}\right\}\left(75 \mathrm{MHz}, \mathrm{DMSO}-\mathrm{d}_{6}\right): 163.04$ (s, $2 \mathrm{C}$, C1), 147.14 (s, 2 C, C2), 141.62 (s, 2 C, C7), 123.06 (s, 2 C, C5), 120.54 (s, 2 C, C4), 114.52 (s, 2 C, C6), 108.45 (s, 2 C, C3); EI-MS, $m / z$ (\%): 251 (100) $[\mathrm{M}]^{+}$.

\section{Metallation reactions}

To a solution of the corresponding ligand 1, 2 or 3 (1.00 eq.) in toluene a slight excess of the pure organometallic reactant $\mathrm{AlMe}_{3}$ and $n \mathrm{BuLi}$, respectively, (1.10 eq.) was slowly added at $0{ }^{\circ} \mathrm{C}$. The reaction mixture was stirred overnight and allowed to warm to rt. Afterwards the volume of the solution was reduced to a few $\mathrm{mL}$ and the resulting concentrated solution stored at $-32{ }^{\circ} \mathrm{C}$ in a refrigerator. Overnight crystals suitable for X-ray diffraction experiments could be obtained. The crystals thus formed were filtered, washed twice with pre-cooled toluene or hexane $\left(0^{\circ} \mathrm{C}\right)$ and finally dried in vacuum. The 
given yields below are just based on the received crystals unless stated otherwise. No further improvement of the yields was attempted because the solutions might have contained impurities upon repeated precipitation.

$\left[\mathrm{Me}_{2} \mathrm{Al}\left\{\left(\mathrm{NCSC}_{6} \mathrm{H}_{4}\right)_{2} \mathbf{N}\right\}\right]$ (4). 1 (274 mg, $1.00 \mathrm{mmol}, 1.00$ eq.) dissolved in toluene $(60 \mathrm{~mL})$ and trimethyl aluminium ( $0.11 \mathrm{~mL}, 79 \mathrm{mg}, 1.10 \mathrm{mmol}, 1.10$ eq.) were treated like stated in the general procedure above. Pale green crystals were obtained in a yield of $80 \mathrm{mg}$ ( $0.24 \mathrm{mmol}, 24 \%$; not optimised). Anal. Calcd. for $\mathrm{C}_{16} \mathrm{H}_{14} \mathrm{AlN}_{3} \mathrm{~S}_{2}\left(339.41 \mathrm{~g} \mathrm{~mol}^{-1}\right)$ : C, 56.62; H, 4.16; N, 12.38; S, 18.89. Found: C, 56.53; H, 4.40; N, 14.44; S, 19.03; $\delta^{1} \mathrm{H}\left(300 \mathrm{MHz}\right.$, thf-d $\left.\mathrm{d}_{8}\right): 7.78\left(\mathrm{~d},{ }^{3} \mathrm{~J}_{\mathrm{HH}}=7.9 \mathrm{~Hz}, 2 \mathrm{H}, \mathrm{H} 3\right)$, $7.66\left(\mathrm{~d},{ }^{3} \mathrm{~J}_{\mathrm{HH}}=7.7 \mathrm{~Hz}, 2 \mathrm{H}, \mathrm{H6}\right), 7.47\left(\mathrm{t},{ }^{3} \mathrm{~J}_{\mathrm{HH}}=7.8 \mathrm{~Hz}, 2 \mathrm{H}, \mathrm{H} 5\right)$, $7.32\left(\mathrm{t},{ }^{3} J_{\mathrm{HH}}=7.7 \mathrm{~Hz}, 2 \mathrm{H}, \mathrm{H} 4\right),-0.42(\mathrm{~s}, 6 \mathrm{H}, \mathrm{H} 1 \mathrm{M}) ; \delta^{13} \mathrm{C}\left\{{ }^{1} \mathrm{H}\right\}$ (75 MHz, thf-d s) $^{2} 174.27$ (s, 2 C, C1), 146.48 (s, 2 C, C7), 129.39 (s, 2 C, C2), 127.81 (s, 2 C, C5), 125.26 (s, 2 C, C4), 123.10 (s, 2 C, C3), 117.00 (s, 2 C, C6), -9.64 (s, 2 C, C1M); $\delta^{15} \mathrm{~N}\left\{{ }^{1}{ }^{H}\right\}$ (50 MHz, thf-d $\mathrm{d}_{8}$ ): -196.3 (s); $\delta^{27} \mathrm{Al}\left\{{ }^{1} \mathrm{H}\right\}\left(130 \mathrm{MHz}\right.$, thf-d $\left.\mathrm{d}_{8}\right): 153.6$ (s); EI-MS, $m / z$ (\%): 339 (3) [M] $]^{+}, 324$ (41) $[\mathrm{M}-\mathrm{Me}]^{+}, 309$ (3) $[\mathrm{M}-2 \mathrm{Me}]^{+}, 283(100)\left[\mathrm{M}-\mathrm{AlMe}_{2}\right]^{+}$.

$\left[\mathrm{Me}_{2} \mathrm{Al}\left\{\left(4-\mathrm{MeNCSC}_{6} \mathrm{H}_{3}\right)_{2} \mathbf{N}\right\}\right]$ (5). 2 (311 $\mathrm{mg}, 1.00 \mathrm{mmol}$, 1.00 eq.) dissolved in toluene $(20 \mathrm{~mL})$ and trimethyl aluminium $(0.11 \mathrm{~mL}, 79 \mathrm{mg}, 1.10 \mathrm{mmol}, 1.10$ eq.) were treated like stated in the general procedure above. Colourless crystals were obtained in a yield of $203 \mathrm{mg}(0.55 \mathrm{mmol}, 55 \%$, not optimised). Anal. Calcd. for $\mathrm{C}_{18} \mathrm{H}_{18} \mathrm{AlN}_{3} \mathrm{~S}_{2}\left(367.47 \mathrm{~g} \mathrm{~mol}{ }^{-1}\right)$ : C, 58.83; H, 4.94; N, 11.44; S, 17.45. Found: C, 58.40; H, 5.26; N, 11.30; S, 17.41; $\delta^{1} \mathrm{H}\left(500 \mathrm{MHz}\right.$, thf-d $\left.\mathrm{d}_{8}\right): 7.58-7.54$ (m, $\left.2 \mathrm{H}, \mathrm{H} 3\right)$, $7.10\left(\mathrm{~d},{ }^{3} \mathrm{~J}_{\mathrm{HH}}=7.3 \mathrm{~Hz}, 2 \mathrm{H}, \mathrm{H} 5\right), 7.03\left(\mathrm{t},{ }^{3} \mathrm{~J}_{\mathrm{HH}}=7.6 \mathrm{~Hz}, 2 \mathrm{H}, \mathrm{H} 4\right)$, 2.51 (s, $6 \mathrm{H}, \mathrm{H} 15),-0.52$ (s, $6 \mathrm{H}, \mathrm{H} 1 \mathrm{M}) ; \delta^{13} \mathrm{C}\left\{{ }^{1} \mathrm{H}\right\}(125 \mathrm{MHz}$, thf-d ${ }_{8}$ ): 173.07 (s, 2 C, C1), 148.79 (s, 2 C, C7), 132.55 (s, 2 C, C2), 127.83 (s, 2 C, C5), 127.12 (s, 2 C, C6), 123.15 (s, 2 C, C4), 119.90 (s, 2 C, C3), 18.85 (s, 2 C, C15), -8.06 (s, 2 C, C1M); $\delta^{27} \mathrm{Al}\left\{{ }^{1} \mathrm{H}\right\}$ (130 MHz, thf-d ${ }_{8}$ ): 181.7 (s); EI-MS, $m / z(\%): 367$ (3) $[\mathrm{M}]^{+}, 352$ (100) $[\mathrm{M}-\mathrm{Me}]^{+}, 336$ (9) $[\mathrm{M}-2 \mathrm{Me}]^{+}, 311$ (54) [M $\left.\mathrm{AlMe}_{2}\right]^{+}$.

$\left[\mathrm{Me}_{2} \mathrm{Al}\left\{\left(4-\mathrm{OMeNCSC}_{6} \mathbf{H}_{3}\right)_{2} \mathbf{N}\right\} \cdot \mathrm{AlMe}_{3}\right]$ (6). $3(343 \mathrm{mg}, 1.00 \mathrm{mmol}$, 1.00 eq.) dissolved in toluene $(40 \mathrm{~mL})$ and trimethyl aluminium $(0.11 \mathrm{~mL}, 79 \mathrm{mg}, 1.10 \mathrm{mmol}, 1.10$ eq.) were treated like stated in the general procedure above. A pale brown powder was obtained in a yield of $119 \mathrm{mg}(0.25 \mathrm{mmol}$, 45\%). Anal. Calcd. for $\mathrm{C}_{21} \mathrm{H}_{27} \mathrm{Al}_{2} \mathrm{~N}_{3} \mathrm{O}_{2} \mathrm{~S}_{2}\left(471.55 \mathrm{~g} \mathrm{~mol}^{-1}\right)$ : C, 53.49; H, 5.77; N, 8.91; S, 13.60. Found: C, 52.52; H, 4.36; N, 10.37; S, 15.49 (deviation due to partial loss of $\mathrm{AlMe}_{3}$ ); $\delta^{1} \mathrm{H}$ (500 MHz, thf- $\left.\mathrm{d}_{8}\right): 7.26\left(\mathrm{dd},{ }^{3} J_{\mathrm{HH}}=8.0,1.2 \mathrm{~Hz}, 2 \mathrm{H}, \mathrm{H} 3\right), 7.21$ $\left(\mathrm{t},{ }^{3} J_{\mathrm{HH}}=8.0 \mathrm{~Hz}, 2 \mathrm{H}, \mathrm{H} 4\right), 6.99\left(\mathrm{dd},{ }^{3} J_{\mathrm{HH}}=8.0,1.1 \mathrm{~Hz}, 2 \mathrm{H}\right.$, H5), 3.97 (s, 6 H, H15), -0.64 (s, 6 H, H1M), -0.95 (s, 9 H, H3M); $\delta^{13} \mathrm{C}\left\{{ }^{1} \mathrm{H}\right\}$ (125 MHz, thf-d (1) $_{8} 173.16$ (s, $2 \mathrm{C}, \mathrm{C} 1$ ), 149.30 (s, 2 C, C6), 137.75 (s, 2 C, C7), 129.91 (s, 2 C, C2), 125.54 (s, 2 C, C4), 114.56 (s, 2 C, C3), 108.32 (s, 2 C, C5), 55.32 (s, 2 C, C15), -5.99 (s, 3 C, C1M), -9.12 (s, 2 C, C3M); $\delta^{27} \mathrm{Al}\left\{{ }^{1} \mathrm{H}\right\}$ (78 MHz, thf- $\mathrm{d}_{8}$ ): 183.3 (s) (second signal not obtained due to broad line width); EI-MS, $m / z$ (\%): 384 (100) $\left[\mathrm{M}-\mathrm{AlMe}_{4}\right]^{+}, 354$ (64) $\left[\mathrm{M}-\mathrm{AlMe}_{4}-\mathrm{OMe}\right]^{+}, 339$ (72) $\left[\mathrm{M}-\mathrm{AlMe}_{4}-\mathrm{OMe}-\mathrm{Me}\right]^{+}$.

$\left[\mathbf{L i}\left\{\left(\mathbf{N C S C}_{6} \mathbf{H}_{3}\right)_{2} \mathbf{N}\right\}\right](7) .1$ (274 mg, $1.00 \mathrm{mmol}, 1.00$ eq.) dissolved in toluene $(60 \mathrm{~mL})$ and $n \mathrm{BuLi}(3.9 \mathrm{~m}$ in hexane,
$0.29 \mathrm{~mL}, 1.10 \mathrm{mmol}, 1.10$ eq.) were treated like stated in the general procedure above. A colourless powder was obtained in a yield of $149 \mathrm{mg}(0.51 \mathrm{mmol}, 51 \%)$. Anal. Calcd for $\mathrm{C}_{14} \mathrm{H}_{8} \mathrm{LiN}_{3} \mathrm{~S}_{2}\left(289.30 \mathrm{~g} \mathrm{~mol}^{-1}\right)$ : C, 58.12; H, 2.79; N, 14.52; S, 22.17. Found: $\mathrm{C}, 57.62 ; \mathrm{H}, 2.42 ; \mathrm{N}, 14.06 ; \mathrm{S}, 20.69 ; \delta^{1} \mathrm{H}$ $\left(500 \mathrm{MHz}\right.$, thf- $\left.\mathrm{d}_{8}\right): 7.52\left(\mathrm{~d},{ }^{3} \mathrm{JHH}_{\mathrm{HH}}=7.6 \mathrm{~Hz}, 2 \mathrm{H}, \mathrm{H} 3\right), 7.33\left(\mathrm{~d},{ }^{3} J_{\mathrm{HH}}\right.$ $=7.9 \mathrm{~Hz}, 2 \mathrm{H}, \mathrm{H6}), 7.16\left(\mathrm{t},{ }^{3} J_{\mathrm{HH}}=7.3 \mathrm{~Hz}, 2 \mathrm{H}, \mathrm{H} 5\right), 6.98\left(\mathrm{t},{ }^{3} J_{\mathrm{HH}}\right.$

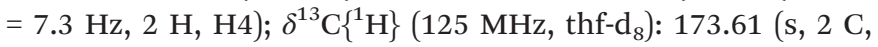
C1), 153.83 (s, 2 C, C7), 132.35 (s, 2 C, C2), 125.65 (s, 2 C, C5), 121.77 (s, 2 C, C4), 121.51 (s, 2 C, C3), 117.37 (s, 2 C, C6); $\delta^{15} \mathrm{~N}$ $\left\{{ }^{1} \mathrm{H}\right\}\left(50 \mathrm{MHz}\right.$, thf- $\left.\mathrm{d}_{8}\right):-155.61$ (s); $\delta^{7} \mathrm{Li}\left\{{ }^{1} \mathrm{H}\right\}\left(117 \mathrm{MHz}\right.$, thf- $\left.\mathrm{d}_{8}\right)$ : -0.22 (s); EI-MS, $m / z(\%): 289$ (59) [M] $]^{+}, 283$ (100) [M - Li] $]^{+}$.

$\left[\operatorname{Li}\left\{\left(4-\mathrm{MeNCSC}_{6} \mathrm{H}_{3}\right)_{2} \mathbf{N}\right\}\right]_{4}$ (8). 2 (311 mg, $1.00 \mathrm{mmol}, 1.00$ eq.) dissolved in toluene $(20 \mathrm{~mL})$ and $n \mathrm{BuLi}(3.9 \mathrm{~m}$ in hexane, $0.29 \mathrm{~mL}, 1.10 \mathrm{mmol}, 1.10 \mathrm{eq}$.) were treated like stated in the general procedure above. Colourless crystals were obtained in a yield of $122 \mathrm{mg}(0.38 \mathrm{mmol}, 38 \%)$. Anal. Calcd for $\mathrm{C}_{16} \mathrm{H}_{12} \mathrm{LiN}_{3} \mathrm{~S}_{2}\left(317.36 \mathrm{~g} \mathrm{~mol}^{-1}\right): \mathrm{C}, 60.55 ; \mathrm{H}, 3.81 ; \mathrm{N}, 13.24$. Found: C, 61.97; H, 4.05; N, 12.27; S, 17.40 (deviation due to remaining toluene); $\delta^{1} \mathrm{H}\left(300 \mathrm{MHz}\right.$, thf- $\left.\mathrm{d}_{8}\right): 7.41\left(\mathrm{~d},{ }^{3} J_{\mathrm{HH}}=8.2\right.$ $\mathrm{Hz}, 2 \mathrm{H}, \mathrm{H} 3), 7.01\left(\mathrm{~d},{ }^{3} J_{\mathrm{HH}}=7.1 \mathrm{~Hz}, 2 \mathrm{H}, \mathrm{H} 5\right), 6.86\left(\mathrm{t},{ }^{3} J_{\mathrm{HH}}=7.5\right.$ $\mathrm{Hz}, 2 \mathrm{H}, \mathrm{H} 4), 2.58(\mathrm{~s}, 6 \mathrm{H}, \mathrm{H} 15) ; \delta^{13} \mathrm{C}\left\{{ }^{1} \mathrm{H}\right\}\left(75 \mathrm{MHz}\right.$, thf- $\left.\mathrm{d}_{8}\right)$ : 170.87 (s, 2 C, C1), 151.70 (s, 2 C, C7), 132.95 (s, 2 C, C2), 127.61 (s, 2 C, C6), 126.31 (s, 2 C, C5), 120.84 (s, 2 C, C4), 118.83 (s, 2 C, C3), 18.78 (s, 2 C, C15); $\delta^{7} \mathrm{Li}\left\{{ }^{1} \mathrm{H}\right\}(117 \mathrm{MHz}$, thf$\left.\mathrm{d}_{8}\right):-0.68(\mathrm{~s})$; EI-MS, $m / z(\%): 317(5)[\mathrm{M}]^{+}, 311(100)[\mathrm{M}-\mathrm{Li}]^{+}$.

\section{X-ray crystallographic studies}

Single crystals were selected from a Schlenk flask under argon or nitrogen atmosphere and covered with perfluorinated polyether oil on a microscope slide, which was cooled with a nitrogen gas flow using the X-TEMP2 device. ${ }^{36}$ An appropriate crystal was selected using a polarise microscope, mounted on the tip of a MiTeGen๑MicroMount or glass fibre, fixed to a goniometer head and shock cooled by the crystal cooling device. The data for 1-8 were collected from shock-cooled crystals at $100(2) \mathrm{K}$. The data of $\mathbf{1 , 2 , 6}$ and $\mathbf{8}$ were collected on an Incoatec Mo Microsource ${ }^{37}$ and compounds 4 and $\mathbf{5}$ were collected on an Incoatec Ag Microsource, ${ }^{38}$ each equipped with mirror optics and APEX II detector with a D8 goniometer. The data of 3 were measured on a Bruker TXS-Mo rotating anode with mirror optics and APEX II detector with a D8 goniometer. All diffractometers were equipped with a low-temperature device and used either $\mathrm{MoK}_{\alpha}$ radiation of $\lambda=0.71073 \AA$ or $\mathrm{AgK}_{\alpha}$ radiation of $\lambda=0.56086 \AA$. The data were integrated with Saint $^{39}$ and an semi-empirical absorption correction (Sadabs) $^{38}$ was applied. The structures were solved by direct methods (Shelxt) ${ }^{40}$ and refined by full-matrix least-squares methods against $F^{2}$ (Shelxl2014). ${ }^{41}$ All non-hydrogen-atoms were refined with anisotropic displacement parameters. The hydrogen atoms were refined isotropically on calculated positions using a riding model with their $U_{\text {iso }}$ values constrained to equal to 1.5 times the $U_{\text {eq }}$ of their pivot atoms for terminal $\mathrm{sp}^{3}$ carbon atoms and 1.2 times for all other carbon atoms. Disordered moieties were refined using bond lengths restraints and isotropic displacement parameter restraints. 
The positions of the amine hydrogen atoms are taken from the difference Fourier map and refined freely.

Crystallographic data for the structures reported in this paper have been deposited with the Cambridge Crystallographic Data Centre. The CCDC numbers, crystal data and experimental details for the X-ray measurements are listed in the ESI.t

\section{Conflict of interest}

The authors declare no competing financial interest.

\section{Acknowledgements}

Thanks to the Danish National Research Foundation (DNRF93) funded Center for Materials Crystallography (CMC) for partial support and the Land Niedersachsen for providing a fellowship in the GAUSS PhD program.

\section{Notes and references}

1 L. Bourget-Merle, M. F. Lappert and J. R. Severn, Chem. Rev., 2002, 102, 3031-3065.

2 W. W. Schoeller, Inorg. Chem., 2011, 50, 2629-2633.

3 (a) H. Gornitzka and D. Stalke, Angew. Chem., 1994, 106, 695-698, (Angew. Chem., Int. Ed. Engl., 1994, 33, 693-695); (b) H. Gornitzka and D. Stalke, Organometallics, 1994, 13, 4398-4405.

4 (a) M. Pfeiffer, T. Stey, H. Jehle, B. Klüpfel, W. Malisch, V. Chandrasekhar and D. Stalke, Chem. Commun., 2001, 337-338; (b) M. Pfeiffer, F. Baier, T. Stey, D. Leusser, D. Stalke, B. Engels, D. Moigno and W. Kiefer, J. Mol. Model, 2000, 6, 299-311; (c) H. Gornitzka and D. Stalke, Eur. J. Inorg. Chem., 1998, 1998, 311-317; (d) A. Steiner and D. Stalke, Angew. Chem., Int. Ed. Engl., 1995, 107, 19081910; (e) A. Steiner and D. Stalke, Organometallics, 1995, 14, 2422-2429; $(f)$ A. Steiner and D. Stalke, J. Chem. Soc., Chem. Commun., 1993, 444-446.

5 (a) C. Kling, D. Leusser, T. Stey and D. Stalke, Organometallics, 2011, 30, 2461-2463; (b) T. Stey, J. Henn and D. Stalke, Chem. Commun., 2007, 413-415; (c) T. Stey, M. Pfeiffer, J. Henn, S. K. Pandey and D. Stalke, Chem. - Eur. J., 2007, 13, 3636-3642; (d) T. Stey and D. Stalke, Z. Anorg. Allg. Chem., 2005, 631, 2931-2936; (e) L. Mahalakshmi and D. Stalke, in Group 13 Chemistry I, ed. H. W. Roesky and D. A. Atwood, Springer, Berlin, Heidelberg, 2002, ch. 3, vol. 103, pp. 85-115.

6 (a) D.-R. Dauer, M. Flügge, R. Herbst-Irmer and D. Stalke, Dalton Trans., 2015, DOI: 10.1039/C5DT03913D; (b) D.-R. Dauer and D. Stalke, Dalton Trans., 2014, 43, 14432-14439.

7 H. Schödel, C. Näther, H. Bock and F. Butenschön, Acta Crystallogr., Sect. B: Struct. Sci., 1996, 52, 842-853.
8 R. Kempe, Angew. Chem., 2000, 112, 478-504, (Angew. Chem., Int. Ed., 2000, 39, 468-493).

9 (a) S. Michlik and R. Kempe, Chem. - Eur. J., 2010, 16, 13193-13198; (b) B. Blank, S. Michlik and R. Kempe, Chem. - Eur. J., 2009, 15, 3790-3799; (c) B. Blank, S. Michlik and R. Kempe, Adv. Synth. Catal., 2009, 351, 2903-2911.

10 S. Michlik and R. Kempe, Nat. Chem., 2013, 5, 140-144.

11 (a) B. D. Ward and L. H. Gade, Chem. Commun., 2012, 48, 10587-10599; (b) G. Desimoni, G. Faita and K. A. Jørgensen, Chem. Rev., 2011, 111, 284-437.

12 H. Werner, R. Vicha, A. Gissibl and O. Reiser, J. Org. Chem., 2003, 68, 10166-10168.

13 U. Leutenegger, G. Umbricht, C. Fahrni, P. von Matt and A. Pfaltz, Tetrahedron, 1992, 48, 2143-2156.

14 (a) D. C. Sauer, R. L. Melen, M. Kruck and L. H. Gade, Eur. J. Inorg. Chem., 2014, 2014, 4715-4725; (b) D. C. Sauer, H. Wadepohl and L. H. Gade, Inorg. Chem., 2012, 51, 12948-12958; (c) B. K. Langlotz, H. Wadepohl and L. H. Gade, Angew. Chem., 2008, 120, 4748-4752.

15 H. Ben Ammar, J. Le Nôtre, M. Salem, M. T. Kaddachi and P. H. Dixneuf, J. Organomet. Chem., 2002, 662, 63-69.

16 T. Papenfuhs and A. G. Hoechst, Verfahren zur Herstellung von 2,2-Imino-bis-benzthiazol-Verbindungen, DE 2947489 A1, Germany, 1979.

17 (a) J. Overgaard and B. B. Iversen, Charge Density Methods, in Hydrogen Bond Studiesed. ed. D. Stalke, Springer, 2012, vol. 146; (b) E. Arunan, G. R. Desiraju, R. A. Klein, J. Sadlej, S. Scheiner, I. Alkorta, D. C. Clary, R. H. Crabtree, J. J. Dannenberg, P. Hobza, H. G. Kjaergaard, A. C. Legon, B. Mennucci and D. J. Nesbitt, Pure Appl. Chem., 2011, 83, 1619-1636; (c) G. R. Desiraju, Acc. Chem. Res., 2002, 35, 565-573; (d) T. Steiner, Angew. Chem., 2002, 114, 50-80, (Angew. Chem., Int. Ed., 2002, 41, 48-76); (e) T. Steiner, Angew. Chem., Int. Ed., 2002, 114, 50-80; $(f)$ D. Braga, F. Grepioni and G. R. Desiraju, Chem. Rev., 1998, 98, 13751406; $(g)$ G. A. Jeffrey, An Introduction to Hydrogen Bonding, Oxford University Press, New York, 1997; $(h)$ G. A. Jeffrey and W. Saenger, Hydrogen Bonding in Biological Structures, Springer, Berlin, 1991; (i) J. Emsley, Chem. Soc. Rev., 1980, 9, 91-124.

18 M. Pfeiffer, A. Murso, L. Mahalakshmi, D. Moigno, W. Kiefer and D. Stalke, Eur. J. Inorg. Chem., 2002, 2002, 3222-3234.

19 J. Hey, D. Leusser, D. Kratzert, H. Fliegl, J. M. Dieterich, R. A. Mata and D. Stalke, Phys. Chem. Chem. Phys., 2013, 15, 20600-20610.

20 A. Walli, S. Dechert and F. Meyer, Eur. J. Org. Chem., 2013, 7044-7049.

21 (a) P. Müller, R. Herbst-Irmer, A. L. Spek, T. R. Schneider and M. R. Sawaya, Crystal Structure Refinement A Crystallographer's Guide to SHELXL, Oxford University Press, New York, 2006; (b) P. Rademacher, Strukturen organischer Moleküle, VCH, Weinheim, 1987.

22 G. R. Desiraju, J. Am. Chem. Soc., 2013, 135, 9952-9967.

23 (a) D. Li, Y. Peng, C. Geng, K. Liu and D. Kong, Dalton Trans., 2013, 42, 11295-11303; (b) M. Stender, B. E. Eichler, 
N. J. Hardman, P. P. Power, J. Prust, M. Noltemeyer and H. W. Roesky, Inorg. Chem., 2001, 40, 2794-2799; (c) B. Qian, D. L. Ward and M. R. Smith, Organometallics, 1998, 17, 3070-3076.

24 H. Gornitzka, C. Hemmert, G. Bertrand, M. Pfeiffer and D. Stalke, Organometallics, 2000, 19, 112-114.

25 (a) M. M. Meinholz, S. K. Pandey, S. M. Deuerlein and D. Stalke, Dalton Trans., 2011, 40, 1662-1671; (b) M. M. Meinholz and D. Stalke, Eur. J. Inorg. Chem., 2011, 2011, 4578-4584; (c) A. Murso and D. Stalke, Dalton Trans., 2004, 2563-2569; (d) F. Baier, Z. Fei, H. Gornitzka, A. Murso, S. Neufeld, M. Pfeiffer, I. Rüdenauer, A. Steiner, T. Stey and D. Stalke, J. Organomet. Chem., 2002, 661, 111127.

26 E. S. Wallis and F. H. Adams, J. Am. Chem. Soc., 1933, 55, 3838-3851.

27 (a) D. Stalke and E. Carl, in Lithium Compounds in Organic Synthesis, ed. R. Luisi and V. Capriati, Wiley-VCH, Weinheim, 2014, pp. 1-32; (b) H. J. Reich, Chem. Rev., 2013, 113, 7130-7178; (c) V. H. Gessner, C. Däschlein and C. Strohmann, Chem. - Eur. J., 2009, 15, 3320-3334; (d) D. B. Collum, A. J. McNeil and A. Ramirez, Angew. Chem., 2007, 119, 3060-3077, (Angew. Chem., Int. Ed., 2007, 46, 3002-3017); (e) T. Stey and D. Stalke, in The Chemistry of Organolithium Compounds, Wiley, Chichester, 2004, pp. 47-120; (f) M. C. Whisler, S. MacNeil, V. Snieckus and P. Beak, Angew. Chem., Int. Ed., 2004, 43, 22062225, (Angew. Chem., 2004, 116, 2256-2276); (g) B. L. Lucht and D. B. Collum, Acc. Chem. Res., 1999, 32, 10351042.

28 H. Dietrich, J. Organomet. Chem., 1981, 205, 291-299.

29 E. Weiss, T. Lambertsen, B. Schubert, J. K. Cockeroft and A. Wiedenmann, Chem. Ber., 1990, 123, 79-81.

30 (a) T. Kottke and D. Stalke, Angew. Chem., 1993, 105, 619621, (Angew. Chem., Int. Ed. Engl., 1993, 32, 580-582); (b) T. Kottke and D. Stalke, Angew. Chem., Int. Ed. Engl., 1993, 105, 619-621.
31 (a) R. E. Mulvey, Chem. Soc. Rev., 1998, 27, 339-346; (b) K. Gregory, P. v. R. Schleyer and R. Snaith, Adv. Inorg. Chem., 1991, 37, 47-142; (c) R. E. Mulvey, Chem. Soc. Rev., 1991, 20, 167-209; (d) D. R. Armstrong, D. Barr, R. Snaith, W. Clegg, R. E. Mulvey, K. Wade and D. Reed, J. Chem. Soc., Dalton Trans., 1987, 1071-1081.

32 (a) R. G. Pearson, J. Am. Chem. Soc., 1985, 107, 6801-6806; (b) R. G. Parr and R. G. Pearson, J. Am. Chem. Soc., 1983, 105, 7512-7516.

33 Georg-August-Universität Göttingen, Virtuelles Labor, http://www.stalke.chemie.uni-goettingen.de/virtuelles_labor/ advanced/13_de.html.

34 Georg-August-Universität Göttingen, Virtuelles Labor, http://www.stalke.chemie.uni-goettingen.de/virtuelles_labor/ nmr/de.html.

35 S. Parsons, H. D. Flack and T. Wagner, Acta Crystallogr., Sect. B: Struct. Sci., 2013, 69, 249-259.

36 (a) D. Stalke, Chem. Soc. Rev., 1998, 27, 171-178; (b) T. Kottke, R. J. Lagow and D. Stalke, J. Appl. Crystallogr., 1996, 29, 465-468; (c) T. Kottke and D. Stalke, J. Appl. Crystallogr., 1993, 26, 615-619; (d) Georg-August-Universität Göttingen, Virtuelles Labor, http://www.stalke.chemie. uni-goettingen.de/virtuelles_labor/special/22_de.html.

37 T. Schulz, K. Meindl, D. Leusser, D. Stern, J. Graf, C. Michaelsen, M. Ruf, G. M. Sheldrick and D. Stalke, J. Appl. Crystallogr., 2009, 42, 885-891.

38 L. Krause, R. Herbst-Irmer, G. M. Sheldrick and D. Stalke, J. Appl. Crystallogr., 2015, 48, 3-10.

39 Bruker AXS Inc., in Bruker Apex CCD, SAINT v8.30C, ed. Bruker AXS Inst. Inc., WI, USA, Madison, 2013.

40 G. Sheldrick, Acta Crystallogr., Sect. A: Fundam. Crystallogr., 2015, 71, 3-8.

41 (a) G. Sheldrick, Acta Crystallogr., Sect. C: Cryst. Struct. Commun., 2015, 71, 3-8; (b) G. M. Sheldrick, Acta Crystallogr., Sect. A: Fundam. Crystallogr., 2014, 70, C1437; (c) G. M. Sheldrick, Acta Crystallogr., Sect. A: Fundam. Crystallogr., 2008, 64, 112-122. 